\title{
Video Oyunların Eğitim Araştırmalarında Kullanımı: Bir Sistematik Tarama ${ }^{1}$
}

\author{
Hakan ALTINPULLUK ${ }^{2}$
}

Makale Türü: Araştırma Makalesi

\begin{abstract}
Öz
Bu araştırmada video oyunların eğitim araştırmalarındaki mevcut durumunun incelenmesi ve araştırma eğilimlerinin belirlenmesi amaçlanmıştır. 2007-2019 yılları arasında yayınlanan ve başlğ̆ında "video oyunları" anahtar sözcükleri olan, Web of Science veritabanında Social Sciences Citation Index (SSCI) indeksli 67 makalenin sistematik tarama yöntemiyle incelenmesiyle araştırma gerçekleştirilmiştir. Araştırma sonucunda, 2017 ve 2019 yıllarında yayın sayılarının en üst noktaya ulaștığı, en fazla Fen Bilimleri alanında video oyunlar araştırmalarının yapıldı̆̆ı, en çok duyuşsal ve motivasyonel öğrenme çıktılarının elde edildiği ve oyunların en çok video oyun konsollarında oynandığ bulgusuna ulaşılmıştır. Kullanılan araştırma yöntemine ilişkin bulgular incelendiğinde, en çok nicel yöntemin tercih edildiği, veri toplama aracı olarak en çok testlerin kullanıldığı, örneklem grubu olarak ilköğretim öğrencilerinin seçildiği bulgusuna ulaşılmıştır. Kuramsal yaklaşımlara ilişkin ise oyun tabanlı öğrenme yaklaşımının en fazla tercih edilen öğrenme yaklaşımı olduğu belirlenmiştir. Ayrıca, araştırma bulgularına dayalı olarak bazı önerilerde bulunulmuştur.
\end{abstract}

Anahtar Kelimeler: Eğilimler, Eğitim Araştırmaları, Video Oyunları, Sistematik Tarama

Atıf: Altınpulluk, H. (2021). Video oyunların eğitim araştırmalarında kullanımı: Bir sistematik tarama. Anadolu Üniversitesi Sosyal Bilimler Dergisi, 21(1), 185-212.

\footnotetext{
1 Bu araştırma kapsamında, "Anadolu Üniversitesi Sosyal ve Beşeri Bilimler Bilimsel Araştırma ve Yayın Etiği Kurulu”na başvuru yapılmış olup, 10.09.2020 Evrak Kayıt Tarihli ve 53291 Protokol No’lu “Olumlu” Karar Belgesi alınmıștır.

2 Anadolu Üniversitesi Açıköğretim Fakültesi Uzaktan Eğitim Bölümü, hakanaltinpulluk@anadolu.edu.tr, ORCID: 0000-0003-4701-1949
} 


\title{
The Use of Video Games in Educational Researches: A Systematic Review
}

\author{
Hakan ALTINPULLUK ${ }^{3}$
}

\begin{abstract}
In this study, it is aimed to examine the current situation of video games in educational research and to determine research trends. The research was carried out by systematically reviewing 67 articles with Social Sciences Citation Index (SSCI) in the Web of Science database, published between 2007 and 2019, with the keywords "video games" in the title. According to the results obtained from the findings, in 2017 and 2019, the number of publications reached the highest point, video games researches were made in the most science fields, mostly affective and motivational learning outcomes were obtained, the games are played mostly in video game consoles. When the findings regarding the research method used are examined, quantitative methods are preferred as the method, the most common tests are used as the data collection tool, primary school students are selected as the sample group. Regarding to the theoretical approaches, it was determined that the game-based learning approach was the most preferred learning approach. In addition, some suggestions were made based on the findings of this research.
\end{abstract}

Keywords: Trends, Educational Researches, Video Games, Systematic Review

\footnotetext{
${ }^{3}$ Anadolu University Open Education Faculty Distance Education Department, hakanaltinpulluk@anadolu.edu.tr, ORCID: 0000-0003-4701-1949
} 


\section{Giriş}

Oyunlar insanlık tarihinde hep var olan bir etkinlik olarak günlük rutinin dışına çıkmak için eğlenceli bir rahatlama yolu olarak görülmekteydi (Kuss ve Griffiths, 2012). Huizinga (1949), ünlü eseri “Homo Ludens”'te oyunların kültürleri de şekillendirdiğini ve toplumsal değişimlere yol açtığını belirtmiştir. İnsanlığa yönelik bir içgüdü olan oyun kavramının farklı dönemlerde farklı rollerde karşımıza çıtığı görülmektedir (Sezgin, Bozkurt, Yılmaz ve van der Linden, 2018).

Bir oyun türü olan video oyunları, kişisel bilgisayarlar, oyun konsolları, akıllı telefon veya tablet gibi bir cihazda oynatılabilen elektronik oyunlar olarak tanımlanmaktadır (Haaranen, Rissanen, Laatikainen ve Kauhanen, 2014). Video oyunlar ilk kez 1970'lerde ortaya çıkmasından bu yana çok yol kat etmiş ve bugün fotogerçekçi grafikler ve üst düzey simülasyonlar sunmaktadır (Statista, 2019a). Son dönemlerde yaygınlaşmasından dolayı, artık kendi başına temel bir okuryazarlık olarak düşünülebilen video oyunları (Gower ve McDowall, 2012), sanat, tasarım, bilim-teknoloji ve pazarlama tekniklerinin birlikte kullanılmasıyla önemli bir metaya dönüşmüş ve beklentilerin sürekli büyümesiyle video oyun teknolojisi büyük bir hızla gelişmiştir (Okur ve Aygenc, 2017). Adams, Margaron ve Kaplan'a (2012) göre, video oyun endüstrisi, motor, görsel ve bilişsel koordinasyon gerektiren çeşitli senaryoların fotogerçekçi simülasyonlarını sunarak son yıllarda giderek daha popüler hale gelmiştir.1980'lerde mütevazi bir başlangıç ile niş bir pazar olarak ortaya çıkan video oyunları dünya çapında muazzam bir atılımla milyonlarca dolarlık bir endüstri haline gelmiştir (Phan ve Tan, 2017). Akıllı telefonlar ve tablet bilgisayarlar gibi dijital teknolojilerin gittikçe yaygınlaşması, toplumların video oyunlarına maruz kalmasına ve endüstrinin büyümesine neden olmuştur (Palaus, Marron, Viejo-Sobera ve Redolar-Ripoll, 2017).

Statista (2019b) verilerine göre, 2012 yılında 70.6 milyar ABD doları olan video oyun endüstrisinin pazar değeri, 2020 yılında 165.9 milyar ABD doları olarak büyük bir yükseliş göstermiştir. 2021 yılında bu pazar değerinin 180 milyar ABD dolarının üzerinde olması beklenmektedir. Yine Statista (2020) verilerine göre, 2020 yılında 27.5 milyon ABD doları olan pazar hacmiyle, en büyük gelir Çin'dedir. Bu ülkeyi ABD, Japonya, Güney Kore ve İngiltere izlemektedir. Aynı kaynaktan elde edilen verilere göre, 2019 yılında video oyun kullanıcılarının \%61'i erkeklerden oluşmakta ve oyuncuların \%37.6'sı düşük gelir grubunda yer almaktadır. Dünya çapında aktif oyuncu sayısı 2020 yılında dünya çapında 2,69 milyar iken, 2023 yılında bu sayının 3,07 milyar kişiye çıkacağı tahmin edilmektedir (Statista, 2021).

Oyunların eğitimde kullanımı yani oyun tabanlı öğrenme yaklaşımının yeni olmadığı ve 1960'lara dayandığı gözlenmektedir (Piaget, 1962). Eğitsel video oyunlarının kullanımı, son yıllarda çevrimiçi ağlar, tabletler ve akıllı telefonlar gibi yeni teknolojik gelişmelerle desteklenmiştir (Sánchez-Mena, Martí-Parreño ve AldásManzano, 2019). Eğitsel video oyunlarının etkinliği ve faydaları birçok farklı alanda kanıtlanmıştır (Manero ve diğerleri, 2015). Araştırmalar, video oyunlarının öğrencinin performansı ve öğrenmeye karşı tutumu üzerinde olumlu etkileri olduğunu göstermektedir (Beserra ve diğerleri, 2014; Israel, Wang ve Marino, 2016; Lieury, Lorant, Trosseille, Champault ve Vourc'h, 2016). Ek olarak, video oyunlarının öğrenmeye ve okula karşı olumlu bir tutum geliştirebildiğine de inanılmaktadır (Durkin ve Barber, 2002). Video oyunları öğrenme süreçlerinde bilgi ve içerik aktarımı açısından faydalı etkinlikler olarak bazı araştırmalarda dikkat çekmektedir. Video oyunlarının

- Fen Bilimleri (Corredor, Gaydos ve Squire, 2014; Garneli ve Chorianopoulos, 2018; Lookadoo ve diğerleri, 2017; Sun, Ye ve Wang, 2015; Ye, Hsiao ve Sun, 2018)

- Matematik (Beserra, Nussbaum ve Oteo, 2019; Beserra, Nussbaum, Zeni, Rodriguez ve Wurman, 2014; Masek, Boston, Lam ve Corcoran, 2017)

- Müzik (Gower ve McDowall, 2012; Hutton ve Sundar, 2010; Paney, 2015) 
- Dil (Chen ve Yang, 2013; Ibrahim, 2019)

- Psikoloji (Ceranoğlu, 2010; You, Kim ve No, 2015)

- Tip Eğitimi (Adams, Margaron ve Kaplan, 2012; Kron, Gjerde, Sen ve Fetters, 2010)

gibi pek çok eğitsel alanda uygulandığı görülmektedir. Ayrıca, eğitim alanında video oyunlarının kullanımıyla ilgili

- Uzamsal becerileri (Martin-Gutierrez, Luis Saorin, Martin-Dorta ve Contero, 2009),

- Akademik katılımı (Marino ve diğerleri, 2014; Ouariachi, Olvera-Lobo, Gutiérrez-Pérez ve Maibach, 2019),

- Duygusal farkındalık ve derse yönelik algıları (Gallup ve Serianni, 2017),

- İşbirlikçi öğrenmeye yönelik tutumları (Del Pozo, Gómez-Pablos ve Muñoz-Repiso, 2017),

- Akademik başarıları (Hawkins, Ratan, Blair ve Fordham, 2019),

- Motor becerileri (Bonney, Jelsma, Ferguson ve Smits-Engelsman, 2017),

- Bilişsel süreçleri (Lieury ve diğerleri, 2016),

- Sosyal becerileri (Hanghøj, Lieberoth ve Misfeldt, 2018),

- Motivasyonları (Kenny ve McDaniel, 2011) ne şekilde etkilediğini inceleyen pek çok çalışma bulunmaktadır.

Video oyunları başta gençler olmak üzere, toplumda giderek popülerliği artan bir faaliyet olarak, yalnızca bir eğlence aracı değil, bir araştırma aracı veya bir çalışma alanı olarak potansiyel taşımaktadır (Palaus ve diğerleri, 2017). Dijital video oyunlarının yaygınlaşması ile eğitimdeki potansiyellerine yönelik araştırmacıların da dikkatini çektiği görülmektedir (Chen ve Yang, 2013). Son yıllarda öğrenme süreçlerinde etkin kullanım alanı bulan video oyunlarla ilgili eğitim alanı dışında bazı içerik analizi (Brand ve diğerleri, 2003; Bullen, Katchabaw ve Dyer-Witheford, 2006; Phan ve Than, 2017; Schmierbach, 2009; Watson, Alber, Barnett, Mercado ve Bernhardt, 2016) veya sistematik tarama (Barnett, Cerin ve Baranowski, 2011; Haaranen ve diğerleri, 2014; Lu ve Kharrazi, 2017; Zeng, Pope, Lee ve Gao, 2017) çalışmaları yapıldığı görülmektedir.

Video oyunlarının eğitim alanındaki kullanımını araştıran ve bu alandaki yayınların analiz edildiği bazı sistematik tarama, içerik analizi, meta analiz ve alanyazın taraması çalışmaları da gerçekleştirilmiştir. Bu araştırmaları içeren Tablo 1 aşağıda gösterilmektedir:

Tablo 1

Video Oyunlarının Eğitim Alanında Analiz Edildiği Bazı Çalışmalar

\begin{tabular}{|c|c|c|c|c|c|}
\hline Yayın & $\begin{array}{l}\text { Analiz } \\
\text { Edilen } \\
\text { Yillar }\end{array}$ & $\begin{array}{l}\text { Analiz } \\
\text { Türüi }\end{array}$ & $\begin{array}{l}\text { İncelenen Veritabanı } \\
\text { ve Indeksler }\end{array}$ & $\begin{array}{l}\text { Íncelenen } \\
\text { Çalışma } \\
\text { Sayısı }\end{array}$ & $\begin{array}{l}\text { İncelenen } \\
\text { Konu }\end{array}$ \\
\hline $\begin{array}{l}\text { Bediou, B., Adams, D. M., } \\
\text { Mayer, R. E., Tipton, E., } \\
\text { Green, C. S. ve Bavelier, } \\
\text { D. (2018). Meta-analysis } \\
\text { of action video game } \\
\text { impact on perceptual, } \\
\text { attentional, and cognitive } \\
\text { skills. Psychological } \\
\text { Bulletin, 144(1), } 77-110 . \\
\text { doi: } 10.1037 / \text { bul0000130 }\end{array}$ & $\begin{array}{l}2000- \\
2015\end{array}$ & $\begin{array}{l}\text { Meta } \\
\text { analiz }\end{array}$ & $\begin{array}{l}\text { PsycINFO, } \\
\text { PsyINDEX, ERIC, } \\
\text { FRANCIS, MEDLINE, } \\
\text { SCOPUS, Web of } \\
\text { Science, ScienceDirect }\end{array}$ & 82 & $\begin{array}{l}\text { Aksiyon } \\
\text { video } \\
\text { oyunların } \\
\text { algisal, } \\
\text { dikkat ve } \\
\text { bilişsel } \\
\text { becerilere } \\
\text { etkisi }\end{array}$ \\
\hline
\end{tabular}


Tablo 1

Video Oyunlarının Eğitim Alanında Analiz Edildiği Bazı Çalışmalar (Devamı)

\begin{tabular}{|c|c|c|c|c|c|}
\hline Yayın & $\begin{array}{l}\text { Analiz } \\
\text { Edilen } \\
\text { Yıllar }\end{array}$ & $\begin{array}{l}\text { Analiz } \\
\text { Türüi }\end{array}$ & $\begin{array}{l}\text { Incelenen Veritabanı } \\
\text { ve Indeksler }\end{array}$ & $\begin{array}{l}\text { İncelenen } \\
\text { Çalışma } \\
\text { Sayısı }\end{array}$ & $\begin{array}{l}\text { İncelenen } \\
\text { Konu }\end{array}$ \\
\hline $\begin{array}{l}\text { Sánchez-Mena, A. ve } \\
\text { Martí-Parreño, J. (2017). } \\
\text { Teachers acceptance of } \\
\text { educational video games: } \\
\text { A comprehensive } \\
\text { literature review. Journal } \\
\text { of e-Learning and } \\
\text { Knowledge Society, 13(2). } \\
\text { doi: 10.20368/1971- } \\
8829 / 1319\end{array}$ & -2017 & $\begin{array}{l}\text { Kapsamlı } \\
\text { literatür } \\
\text { incelemes } \\
\text { i }\end{array}$ & $\begin{array}{l}\text { Web of Science, } \\
\text { Scopus }\end{array}$ & 11 & $\begin{array}{l}\text { Öğretmen } \\
\text { lerin } \\
\text { eğitsel } \\
\text { video } \\
\text { oyunlarını } \\
\text { kabulü }\end{array}$ \\
\hline $\begin{array}{l}\text { Kangas, M., Koskinen, A. } \\
\text { ve Krokfors, L. (2017). A } \\
\text { qualitative literature } \\
\text { review of educational } \\
\text { games in the classroom: } \\
\text { The teacher's pedagogical } \\
\text { activities. Teachers and } \\
\text { Teaching, 23(4), 451-470. } \\
\text { doi:10.1080/13540602.20 } \\
\text { 16.1206523 }\end{array}$ & $\begin{array}{l}1998- \\
2013\end{array}$ & $\begin{array}{l}\text { Nitel } \\
\text { alanyazın } \\
\text { taraması }\end{array}$ & $\begin{array}{l}\text { ScienceDirect, } \\
\text { PsycINFO, Proquest, } \\
\text { PsycARTICLES, Ovid, } \\
\text { Project Muse, } \\
\text { EBSCO, ERIC, } \\
\text { Proquest, SocINDEX, } \\
\text { SpringerLink }\end{array}$ & 35 & $\begin{array}{l}\text { Sinıfta } \\
\text { eğitsel } \\
\text { oyunlar }\end{array}$ \\
\hline 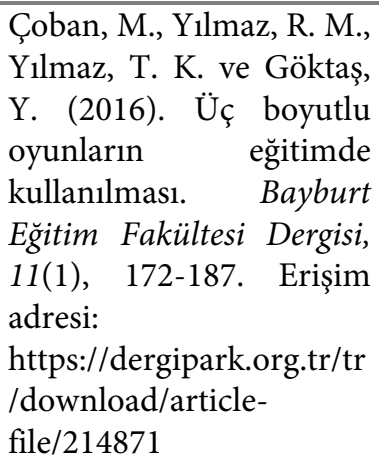 & $\begin{array}{l}2009- \\
2013\end{array}$ & $\begin{array}{l}\text { İçerik } \\
\text { analizi }\end{array}$ & SSCI veya SCI & 28 & $\begin{array}{l}\text { 3B video } \\
\text { oyunlar }\end{array}$ \\
\hline $\begin{array}{l}\text { Clark, D. B., Tanner- } \\
\text { Smith, E. E. ve } \\
\text { Killingsworth, S. S. } \\
(2016) \text { Digital games, } \\
\text { design, and learning: A } \\
\text { systematic review and } \\
\text { meta-analysis. Review of } \\
\text { Educational Research, } \\
86(1) \text {, 79-122. doi: } \\
10.3102 / 00346543155820 \\
65\end{array}$ & $\begin{array}{l}2000- \\
2012\end{array}$ & $\begin{array}{l}\text { Sistemati } \\
\mathrm{k} \text { tarama } \\
\text { ve meta } \\
\text { analiz }\end{array}$ & $\begin{array}{l}\text { ISI Web of Science } \\
\text { (SCI, SSCI), Proquest, } \\
\text { ERIC, PsycINFO, } \\
\text { Social } \\
\text { Abstract, Services } \\
\text { Inspec, Compendex, } \\
\text { IEEE Xplore }\end{array}$ & 69 & $\begin{array}{l}\text { Öğrenme } \\
\text { de dijital } \\
\text { oyunların } \\
\text { tasarımı }\end{array}$ \\
\hline
\end{tabular}


Tablo 1

Video Oyunlarının Eğitim Alanında Analiz Edildiği Bazı Çalışmalar (Devamı)

\begin{tabular}{|c|c|c|c|c|c|}
\hline Yayın & $\begin{array}{l}\text { Analiz } \\
\text { Edilen } \\
\text { Yillar }\end{array}$ & $\begin{array}{l}\text { Analiz } \\
\text { Türüi }\end{array}$ & $\begin{array}{l}\text { Incelenen Veritabanı } \\
\text { ve Indeksler }\end{array}$ & $\begin{array}{l}\text { İncelenen } \\
\text { Çalışma } \\
\text { Sayısı }\end{array}$ & $\begin{array}{l}\text { İncelenen } \\
\text { Konu }\end{array}$ \\
\hline $\begin{array}{l}\text { Boyle, E. A., Hainey, T., } \\
\text { Connolly, T. M., Gray, G., } \\
\text { Earp, J., Ott, M. ... ve } \\
\text { Pereira, J. (2016). An } \\
\text { update to the systematic } \\
\text { literature review of } \\
\text { empirical evidence of the } \\
\text { impacts and outcomes of } \\
\text { computer games and } \\
\text { serious games. Computers } \\
\text { \& Education, 94, 178-192. } \\
\text { doi: } \\
10.1016 / \text { j.compedu.2015. } \\
11.003\end{array}$ & $\begin{array}{l}2009- \\
2014\end{array}$ & $\begin{array}{l}\text { Sistemati } \\
\mathrm{k} \\
\text { alanyazın } \\
\text { taraması }\end{array}$ & $\begin{array}{l}\text { Science Direct, ASSIA, } \\
\text { BioMed Central, } \\
\text { ERIC, Ingenta ve IEEE }\end{array}$ & 143 & $\begin{array}{l}\text { Bilgisayar } \\
\text { oyunları } \\
\text { ve ciddi } \\
\text { oyunlar }\end{array}$ \\
\hline $\begin{array}{l}\text { Caroux, L., Isbister, K., Le } \\
\text { Bigot, L. ve Vibert, N. } \\
\text { (2015). Player-video } \\
\text { game interaction: A } \\
\text { systematic review of } \\
\text { current concepts. } \\
\text { Computers in Human } \\
\text { Behavior, 48, 366-381. } \\
\text { doi: } \\
\text { 10.1016/j.chb.2015.01.06 }\end{array}$ & $\begin{array}{l}2000- \\
2013\end{array}$ & $\begin{array}{l}\text { Sistemati } \\
\mathrm{k} \text { tarama }\end{array}$ & $\begin{array}{l}\text { ACM SIGCHI, SCI- } \\
\text { Expanded, SSCI }\end{array}$ & 72 & $\begin{array}{l}\text { Oyuncu- } \\
\text { video } \\
\text { oyun } \\
\text { etkileşimi }\end{array}$ \\
\hline $\begin{array}{l}\text { Connolly, T. M., Boyle, E. } \\
\text { A., MacArthur, E., } \\
\text { Hainey, T. ve Boyle, J. M. } \\
(2012) \text { A systematic } \\
\text { literature review of } \\
\text { empirical evidence on } \\
\text { computer games and } \\
\text { serious games. Computers } \\
\text { \& Education, 59(2), 661- } \\
\text { 686. doi: } \\
\text { 10.1016/j.compedu.2012. } \\
03.004\end{array}$ & $\begin{array}{l}2004 \\
2009\end{array}$ & $\begin{array}{l}\text { Sistemati } \\
\mathrm{k} \\
\text { alanyazın } \\
\text { taraması }\end{array}$ & 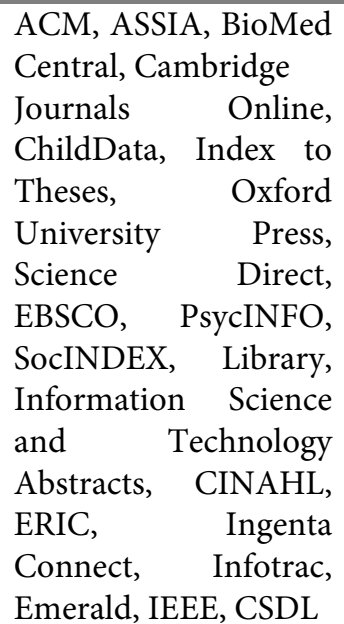 & 129 & $\begin{array}{l}\text { Bilgisayar } \\
\text { oyunlarını } \\
\text { n ve ciddi } \\
\text { oyunların } \\
\text { ampirik } \\
\text { kanitları }\end{array}$ \\
\hline $\begin{array}{l}\text { Papastergiou, M. (2009). } \\
\text { Exploring the potential of } \\
\text { computer and video } \\
\text { games for health and } \\
\text { physical education: A } \\
\text { literature } \\
\text { review. Computers } \\
\text { Education, 53(3), } 603- \\
622 \text {. doi: } \\
10.1016 / \text { j.compedu.2009. } \\
04.001\end{array}$ & $\begin{array}{l}2000- \\
2008\end{array}$ & $\begin{array}{l}\text { Alanyazin } \\
\text { taraması }\end{array}$ & $\begin{array}{l}\text { ISI Web of Knowledge, } \\
\text { EBSCO Host, } \\
\text { SPORTDiscus, } \\
\text { PsycINFO, Green- } \\
\text { FILE, Shock ve } \\
\text { Vibration Digest, } \\
\text { PubMed, ERIC, } \\
\text { EdITLib }\end{array}$ & 34 & $\begin{array}{l}\text { Sağlık ve } \\
\text { beden } \\
\text { eğitimind } \\
\text { e } \\
\text { bilgisayar } \\
\text { video } \\
\text { oyunları }\end{array}$ \\
\hline
\end{tabular}


$\mathrm{Bu}$ araştırma ise incelenen öğeler açısından bazı ortak noktalar olsa da gerek kapsamı gerek incelendiği yıllar açısından daha farklı bir bağlamda gerçekleştirilmiştir. 2007 ve 2019 periyodu gibi görece uzun bir dönemi kapsaması ve güncel çalışmalardaki son durumun tespiti açısından bu araştırmanın sonuçları önemlidir. Ayrıca, alanyazındaki diğer çalışmalardan farklı olarak, video oyunların oynandığı ortamlar, cihazlar, araştırmalarda kullanılan kuramlar/yaklaşımlar/modeller gibi hiçbir çalışmada yer almayan bazı bileşenlerin analiz edilmesi açısından özgün bulgular içermektedir.

Bu araştırmanın amacı, 2007-2019 yılları arasında Web of Science veritabanında SSCI indeksli eğitim bilimleri dergilerinde, başlı̆̆ında "video oyunlar" içeren 67 makalenin sistematik tarama yöntemiyle analiz edilmesiyle, video oyunların eğitimdeki kullanım eğilimlerinin belirlenmesidir. Bu amaca ulaşmak için aşağıdaki araştırma sorularına yanıt aranmıştır:

1. Yıllara göre yayınlanan makale sayılarındaki değişimler nelerdir?

2. Video oyun araştırmalarının eğitsel alanları hangileridir?

3. Video oyun araştırmalarından elde edilen öğrenme çıktıları nelerdir?

Video oyunlara ilişkin boyutlar:

1. Araştırmalardaki video oyunların adları nelerdir?

2. Araştırmalarda kullanılan video oyunların türleri nelerdir?

3. Araştırmalarda kullanılan video oyunların oynandığ cihazlar hangileridir?

4. Video oyunların oynandığ fiziksel ortamlar nelerdir?

Araştırma yöntemlerine ilişkin boyutlar:

1. Video oyun araştırmalarında kullanılan yöntemler nelerdir?

2. Video oyun araştırmalarında kullanılan veri toplama araçları hangileridir?

3. Video oyun araştırmalarında yer alan örneklem grupları hangileridir?

4. Video oyun araştırmalarında kullanılan örneklem sayıları nelerdir?

5. Video oyun araştırmalarında kullanılan kuramlar/yaklaşımlar/modeller hangileridir?

\section{Yöntem}

$\mathrm{Bu}$ araştırmada, video oyunlarıyla ilgili makaleler sistematik olarak taranmıştır. Sistematik tarama, alanında uzman kişiler tarafından araştırma eğilimlerini belirlemek için benzer yöntemler ile yapılmış çok sayıdaki araştırmanın yapılandırılmış ve kapsamlı bir sentezidir (Karaçam, 2014). İdeal olarak, sistematik taramalar, önceden tanımlanmış uygunluk kriterlerine dayanarak, ana hatlarıyla belirtildiği gibi bir metodolojik yaklaşıma göre yürütülür (Moher ve diğerleri, 2015). Sistematik taramalar, seçim kriterlerinin belirlenmesi, ilgili çalışmalar için araştırma yapılması, eleştirel değerlendirme, veri analizi ve sentezi süreçlerini içermektedir (Dybå ve Dingsøyr, 2008).

Bu çalışmada, 2007-2019 yılları arasında SSCI kapsamındaki eğitim bilimleri dergilerinde, başlığında "video games” içeren 67 makalenin analiz edilmesiyle, video oyunlarının eğitim araştırmalarındaki kullanım eğilimlerinin belirlenmesi amaçlanmakta ve mevcut durum ortaya konulmaya çalışılmaktadır. Bu araştırma kapsamında, "Anadolu Üniversitesi Sosyal ve Beşeri Bilimler Bilimsel Araştırma ve Yayın Etiği Kurulu”na başvuru yapılmış olup, 10.09.2020 Evrak Kayıt Tarihli ve 53291 Protokol No’lu “Olumlu” Karar Belgesi alınmıştır. 


\section{Veri Toplama Aracı ve Süreci}

$\mathrm{Bu}$ araştırmada veri toplama aracı olarak, "Web of Science Core Collection" veritabanı kullanılarak, anahtar kelime olarak "video games" sözcüklerini başlığında içeren makalelerin listelenmesi sağlanmıştır. Zaman periyodu (timespan) bölümünde 2007-2019 yılları arasındaki periyod seçilmiş ve "Web of Science Core Collection: Citation Indexes" bölümünde yalnızca "SSCI" seçilmiştir. Bu aşamada 868 çalışma listelenmiştir. Daha sonra açllan sayfada yalnızca makaleler listelenerek, Web of Science kategorilerinde "Education Educational Research or Psychology Educational or Education Special or Education Scientific Disciplines" kutucukları seçilerek yalnızca eğitim bilimleri disiplinine ait makalelerin listelenmesi sağlanmıştır. Bu seçimlerin ardından 69 makale listelenmiş ancak 1 makalenin İspanyolca, 1 makalenin ise Almanca olarak yayınlanmasından dolayı 67 makale son durumda sistematik tarama için belirlenmiştir.

$\mathrm{Bu}$ makalelerin yer aldığı dergiler, dergilerde konuyla ilgili yayınlanmış makale sayısı, derginin 2018 yılı ve 5 yıllık etki faktörü ve kategorisindeki çeyrek (quartile) bilgisi Tablo 2'de gösterilmektedir.

Tablo 2

Makalelerin Yayınlandığı Dergiler

\begin{tabular}{|c|c|c|c|c|}
\hline Dergiler & $\begin{array}{l}\text { Makale } \\
\text { Sayısı }\end{array}$ & $\begin{array}{l}\text { Etki } \\
\text { Faktörüi } \\
2018\end{array}$ & $\begin{array}{l}\text { Etki Faktörü } \\
5 \text { Yıllık }\end{array}$ & $\begin{array}{l}\text { Çeyrek } \\
\text { Kategorisi }\end{array}$ \\
\hline Computers \& Education & 8 & 5.627 & 5.902 & Q1 \\
\hline Journal of Science Education and Technology & 6 & 1.785 & 1.935 & Q2 \\
\hline British Journal of Educational Technology & 4 & 2.588 & 3.028 & Q1 \\
\hline Interactive Learning Environments & 4 & 1.929 & 2.056 & Q2 \\
\hline Educational Technology ve Society & 3 & 2.133 & 2.682 & Q1 \\
\hline Theory into Practice & 3 & 1.347 & 2.199 & Q3 \\
\hline Creativity Research Journal & 2 & 1.13 & 1.645 & Q4 \\
\hline $\begin{array}{l}\text { Educational Technology Research and } \\
\text { Development }\end{array}$ & 2 & 2.115 & 2.672 & Q1 \\
\hline $\begin{array}{l}\text { Eurasia Journal of Mathematics Science and } \\
\text { Technology Education }\end{array}$ & 2 & 0.903 & - & Q3 \\
\hline International Journal of Engineering Education & 2 & 0.611 & 0.676 & Q4 \\
\hline Journal of Computer Assisted Learning & 2 & 2.451 & 3.257 & Q1 \\
\hline Journal of Educational Computing Research & 2 & 1.543 & 1.542 & Q2 \\
\hline Learning Disability Quarterly & 2 & 1.525 & 1.853 & Q2 \\
\hline Diğer $^{*}$ & 25 & - & - & - \\
\hline Toplam & 67 & - & - & - \\
\hline
\end{tabular}

67 makale tam metin olarak bilgisayara indirilmiş ve yıllara göre klasörlenmiştir. Ulaşılan makaleler için "yayın yılı", "eğitsel alanı", "elde edilen öğrenme çıktısı" "video oyunun adı", "video oyunun türü”, "video oyunun oynandığı cihaz", "video oyunun oynandığı ortam”, “araştırma yöntemi”, “veri toplama aracı”, “örneklem grubu”, “örneklem sayısı” ve "kuramlar/yaklaşımlar/modeller” olarak 12 sütunda belirtilmiştir. 67 makaleye ait bilgiler Microsoft Excel tablosuna girilmiştir. 


\section{Verilerin Analizi}

Makalelerin belirlenen kriterlere göre analiz edilmesi ve sınıflandırılmasında, 67 makale sistematik tarama ile analiz edilerek değerlendirilmiştir. Araştırmacı özellikle makalelerde kullanılan araştırma yöntemleri konusunda tereddüt yaşadığı yerlerde araştırmanın güvenirliğini artırmak adına bilimsel araştırma yöntemleri dersi veren gönüllü iki alan uzmanına danışmıştır. Bu iki uzman çalışmaların beşte birini analiz etmiş ve kodlayıcılar arası uyum değeri hesaplanmıştır. Kodlayıcılar arası tutarlılığın hesaplanmasında Miles ve Huberman'ın (1994) Güvenilirlik = Uzlaşma Sayısı / (Toplam Uzlaşma Sayısı + Uzlaşmazlık) formülü kullanılarak uyum düzeyi .87 olarak belirlenmiştir. Alanyazındaki makaleler sistematik taranırken betimleyici istatistiklerden frekanslar kullanılmış ve analizler tablo ve grafiklerle görselleştirilmiştir.

\section{Bulgular}

\section{Yıllara Göre Makale Sayılarındaki Değişim}

Video oyunları başlığında içeren makalelerin yıllara göre dağılımı ile ilgili grafik Şekil 1'de verilmiştir.

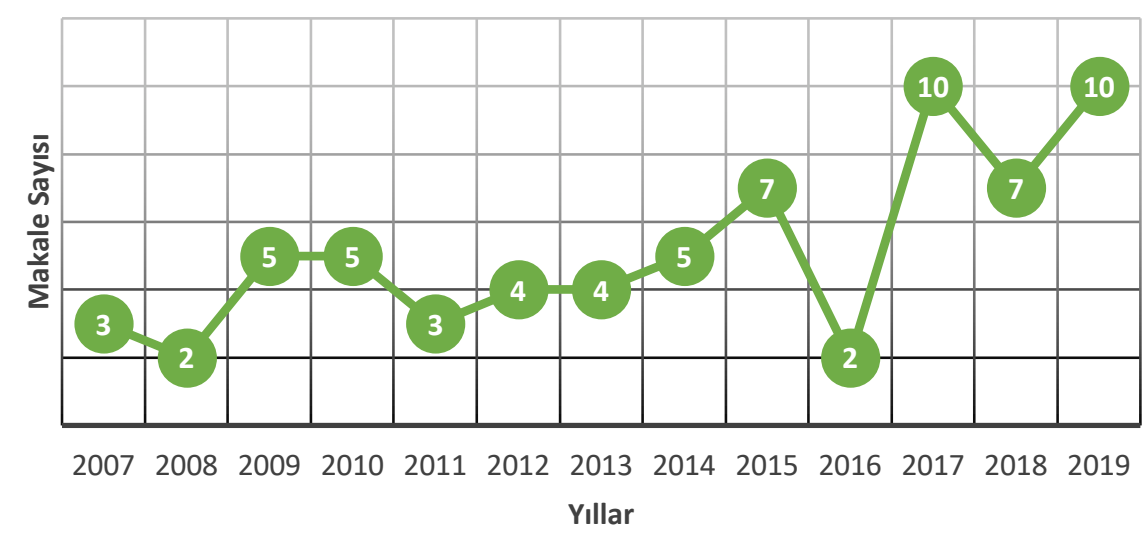

Şekil 1. Yıllara Göre Makale Sayılarındaki Değişim

Eğitim alanında video oyunlarla ilgili gerçekleştirilen SSCI indeksli 67 araştırmanın yıllara göre dağılımı Şekil 1'de gösterilmektedir. Buna göre, 2007 yılında makale sayısının az olmasına rağmen ( $f=3)$, 2008'te bu sayının da düştügü $(\mathrm{f}=2) ; 2009$ ve 2010 yıllarında ise tekrar yükselişe geçtiği $(\mathrm{f}=5)$ anlaşılmaktadır. 2011 yllında ise makale sayısı tekrar düşüş göstermiştir (f=3). 2011'den 2015 yllına kadar doğrusal bir artış gözlenirken, 2016 yılında makale sayılarında büyük bir düşüş göze çarpmaktadır (f=2). Ancak bu düşüşten sonra 2017 yılında en yüksek (f=10) makale sayısına ulaşılmıştır. 2018 yılında tekrar bir düşüş yaşanırken (f=7) 2019 yılında da 2017 yılında olduğu gibi en yüksek sayıda makalenin ( $\mathrm{f}=10)$ SSCI indeksli dergilerde yayınlandığı gözlenmektedir.

\section{Video Oyunların Eğitsel Alanları}

Video oyunların eğitsel alanları ve alt alanları ile ilgili bilgiler Tablo 3’te verilmiştir. 
Tablo 3

Video Oyunların Eğitsel Alanları

\begin{tabular}{lllll}
\hline Eğitim Alanı & Alt Alan & f & Eğitim Alanı & f \\
\hline Fen Bilimleri & Genel & 4 & Dijital okuryazarlık & 1 \\
& Biyoloji & 6 & Ebeveyn eğitimi & 1 \\
& Fizik & 3 & Eleştirel oyun okuryazarlığı & 1 \\
Kimya & 1 & Engelli eğitimi & 1 \\
Matematik eğitimi & & 6 & Fiziksel aktivite eğitimi & 1 \\
Tıp eğitimi & & 4 & Genel lisansüstü becerileri eğitimi & 1 \\
Etik/ ahlak eğitimi & 3 & Mimari eğitimi & 1 \\
Mühendislik eğitimi & 3 & Spor eğitimi & 1 \\
Müzik eğitimi & 3 & Tiyatro oyunculuğu eğitimi & 1 \\
Psikoloji eğitimi & 3 & Verimlilik eğitimi & 1 \\
Dil eğitimi & & Yangın söndürme eğitimi & 1 \\
Grafik tasarımı eğitimi & & Yöneticilik eğitimi & 1 \\
Tarih eğitimi & & 2 & Yurttaşlı eğitimi & 1 \\
Bilgisayar eğitimi & & Belirtilmemiş & 11 \\
\hline *Bă & & &
\end{tabular}

*Bazı makaleler birden fazla eğitim alanında gerçekleştirilmiştir.

Tablo 3'de gösterilen eğitsel alt alanlara bakıldığında oldukça çeşitli eğitim alanlarında video oyunların kullanıldığı anlaşılmaktadır. Bu alanlardan en yoğunu Fen Bilimleri alanıdır. 4'ü Genel, 6'sı Biyoloji, 3’ü Fizik ve 1'i Kimya alt alanı olmak üzere 14 makale video oyunların Fen Bilimlerinde kullanımı üzerinedir. Fen Bilimlerini Matematik takip etmektedir. 6 çalışma Matematik Eğitimi üzerine yayınlanmıştır. Tıp Eğitiminde video oyunların kullanıldığı 4 makale bulunmaktadır. Etik / ahlak, Mühendislik, Müzik ve Psikoloji alanlarında da 3'er çalışma yayınlanmıştır. Dil, Grafik Tasarımı, Tarih ve Bilgisayar Eğitimi de 2'şer çalışmada yer almaktadır.

\section{Video oyunlardan elde edilen öğrenme çıktıları}

Video oyunlardan elde edilen öğrenme çıtıları ile ilgili bilgiler Tablo 4’te verilmiştir.

Tablo 4

Video Oyunlardan Elde Edilen Öğrenme Çıktıları

\begin{tabular}{ll}
\hline Öğrenme Çıktısı & f \\
\hline Duyuşsal ve motivasyonel & 17 \\
Algısal ve bilişsel & 14 \\
Bilgi edinme / İçeriği anlama & 13 \\
Davranış değişikliği & 8 \\
Motor becerileri & 7 \\
Sosyal / yumuşak beceri (social/soft skill) çıktıları & 4 \\
Fizyolojik & 3 \\
Diğer & 1 \\
Toplam & 67 \\
\hline
\end{tabular}

Video oyunlarından elde edilen öğrenme çıktıları incelendiğinde (Tablo 4) en çok video oyunlarının duyuşsal ve motivasyonel $(\mathrm{f}=17)$ etkileriyle ilgili araştırmaların gerçekleştirildiği görülmektedir. Daha sonra algısal ve bilişsel ( $\mathrm{f}=14)$ öğrenme çıtılarının ölçüldügü çalışmalar gerçekleştirilmiştir. Bilgi edinme / içeriği anlama $(\mathrm{f}=13)$, davranış değişikliği $(\mathrm{f}=8)$, motor becerileri $(\mathrm{f}=7)$, sosyal / yumuşak beceri (social / soft skill) çıktıları ve fizyolojik ( $\mathrm{f}=3$ ) çıktıların araştırıldığı makaleler de yer almaktadır. 


\section{Video Oyunların Adı}

Video oyunların adı ile ilgili bilgiler Tablo 5'te verilmiştir.

Tablo 5

Video Oyunların Adı

\begin{tabular}{|c|c|c|c|}
\hline Oyunun Adı & f & Oyunun Adı & f \\
\hline You Make Me Sick! & 3 & Cut the Rope & 1 \\
\hline World of Warcraft & 2 & Dance Dance Revolution & 1 \\
\hline Angry Birds & 2 & Ecity & 1 \\
\hline Minecraft & 2 & Fable III & 1 \\
\hline Cell Command & 2 & Mass Effect II & 1 \\
\hline Crazy Plant Shop & 2 & Fire Captain & 1 \\
\hline Reach for the Sun & 2 & Guitar Hero & 1 \\
\hline Abydos & 1 & SingStar & 1 \\
\hline Assassin's Creed Unity & 1 & Lego Star Wars II & 1 \\
\hline Aion & 1 & MinecraftEdu & 1 \\
\hline Lineage 1 & 1 & Particles! & 1 \\
\hline Sudden Attack & 1 & Perfect Strain & 1 \\
\hline Mabinogi Heroes & 1 & Quest Atlantis & 1 \\
\hline Special Force & 1 & Rock Band & 1 \\
\hline Counter-Strike Online & 1 & Karaoke Revolutions & 1 \\
\hline Diablo 3 & 1 & Soccer heading & 1 \\
\hline Blade and Soul & 1 & Table tilt & 1 \\
\hline TERA & 1 & Ski jump & 1 \\
\hline Queen's Blade & 1 & Bubble Balance & 1 \\
\hline Legend of Souls & 1 & Penguin slide & 1 \\
\hline Alien Game & 1 & Snow board & 1 \\
\hline Bookworm & 1 & KungFu & 1 \\
\hline Baalty & 1 & Perfect 10 & 1 \\
\hline Ballance & 1 & Skateboard & 1 \\
\hline Big Brain Academy & 1 & Space Race & 1 \\
\hline BONE & 1 & Supercharged! & 1 \\
\hline Borderlands 2 & 1 & Tetris & 1 \\
\hline Portal 2 & 1 & The Foolish Lady (La Dama Boba) & 1 \\
\hline Lara Croft and the Guardian of Light & 1 & Torchlight II & 1 \\
\hline Team Fortress 2 & 1 & Wii Sports: Bowling & 1 \\
\hline Gone Home & 1 & X-Men Destiny & 1 \\
\hline Papers, Please & 1 & Prisoner of Echo & 1 \\
\hline Call of Duty 4: Modern Warfare & 1 & Yeni Oyun Üretimi & 2 \\
\hline Civilization III & 1 & Belirtilmemiş & 28 \\
\hline
\end{tabular}

*Bazı çalışmalarda birden fazla video oyunu kullanılmıştır.

Tablo 5'te 67 makalede oynanarak etkileri araştırılan video oyunların bir listesi görülmektedir. Tabloda oyun çeşitliliğinin oldukça fazla olduğu dikkat çekmektedir. Video oyunların isimleriyle ilgili yapılan sistematik taramada "You Make Me Sick!” (f=3) adlı oyun en çok karşımıza çıkan oyun olarak göze çarpmaktadır. Bu oyunu, "World of Warcraft", "Angry Birds", "Minecraft","Cell Command", "Crazy Plant Shop" ve "Reach for the Sun" adlı video oyunları $(\mathrm{f}=2)$ takip etmektedir. Diğer video oyunlarının birer kez araştırmalarda oynandığı görülmektedir. 
Video Oyunların Türü

Video oyunların türü ile ilgili bilgiler Tablo 6'da verilmiştir.

Tablo 6

Video oyunların türü

\begin{tabular}{|c|c|c|c|}
\hline Oyun Ana Türü & Oyun Alt Türü & $\begin{array}{l}\text { Alt } \\
\text { Toplam }\end{array}$ & Toplam \\
\hline Eğitsel oyun / Ciddi (serious) oyun & & & 29 \\
\hline \multirow[t]{9}{*}{ Aksiyon-Macera } & Platform oyunları & 3 & 24 \\
\hline & Nişancı oyunları & 2 & \\
\hline & Dövüş oyunları & 1 & \\
\hline & Gizlilik/gizem (stealth) oyunları & 2 & \\
\hline & Hayatta kalma (survival) oyunları & 3 & \\
\hline & Ritim müzik aksiyon oyunları & 3 & \\
\hline & Korku oyunları & 1 & \\
\hline & $\begin{array}{l}\text { Etkileşimli film / Öykü anlatımı } \\
\text { (storytelling) }\end{array}$ & 4 & \\
\hline & Gerçek zamanlı 3B macera & 5 & \\
\hline \multirow[t]{3}{*}{ Rol oynama (Role-playing) } & $\begin{array}{l}\text { Kitlesel çok oyunculu çevrimiçi rol } \\
\text { oynama oyunları (MMORPG) }\end{array}$ & 7 & 14 \\
\hline & Taktik rol oynama & 1 & \\
\hline & Korumalı alan (sandbox) rol oynama & 6 & \\
\hline \multirow[t]{3}{*}{ Simülasyon } & Yapı simülasyonu & 2 & 11 \\
\hline & Yaşam simülasyonu & 7 & \\
\hline & Araç simülasyonu & 2 & \\
\hline Eşleme - Bulmaca (puzzle) & & & 9 \\
\hline \multirow[t]{3}{*}{ Strateji } & Gerçek zamanlı strateji & 5 & 8 \\
\hline & Tur tabanlı (turn-based) strateji (TBS) & 2 & \\
\hline & Büyük strateji savaş oyunu & 1 & \\
\hline \multirow[t]{3}{*}{ Spor } & Yarış & 2 & 5 \\
\hline & Genel spor & 2 & \\
\hline & Spor temelli dövüş & 1 & \\
\hline $\begin{array}{l}\text { Kitlesel çok oyunculu çevrimiçi oyun } \\
\text { (Massively multiplayer online /MMO) }\end{array}$ & & & 5 \\
\hline Gündelik (Casual) & & & 5 \\
\hline Programlama oyunu & & & 1 \\
\hline Trivia oyunu & & & 1 \\
\hline Belirtilmemiş & & & 20 \\
\hline
\end{tabular}

*Bazı çalışmalarda birden fazla oyun türü bulunmaktadır.

Yapılan sistematik tarama doğrudan eğitim alanındaki video oyunların etkilerinin araştırıldığı araştırmalara dayandığı için, eğitsel oyun veya ciddi oyun adı verilen video oyun türlerinin en yüksek ( $\mathrm{f}=29)$ sayıda karşımıza çıktığı görülmektedir (Tablo 6). Makalelerde bir diğer popular oyun türünün ise aksiyon-macera (f=24) olduğu görülmektedir. Rol oynama oyunları da bir diğer çok oynanan oyun türüdür. Bu oyun türünde Kitlesel Çok Oyunculu Çevrimiçi Rol Oynama Oyunları (Massively Multiplayer Online Role Playing Game-MMORPG) ve korumalı alan oyunlarının popüler olduğu görülmektedir. Rol oynama oyunlarının ardından simülasyon oyunlarının yoğunlukla (f=11) kullanıldığı görülmektedir. Simülasyon oyunlarının da alt kümesi olan yaşam simülasyonu oyunları da $(\mathrm{f}=7)$ en çok oynanan simülasyon oyun türü olarak göze çarpmaktadır. Eşleme - 
bulmaca (puzzle) oyunları $(\mathrm{f}=9)$, strateji $(\mathrm{f}=8)$, spor $(\mathrm{f}=5)$, kitlesel çok oyunculu çevrimiçi oyun (massively multiplayer online /MMO) $(\mathrm{f}=5)$, gündelik (casual) $(\mathrm{f}=5)$, programlama $(\mathrm{f}=1)$ ve önemsiz (trivia) $(\mathrm{f}=1)$ video oyunları diğer oyun türleri olarak dikkat çekmektedir.

\section{Video Oyunların Oynandığı Cihazlar}

Video oyunların oynandığı cihazlar ile ilgili bilgiler Tablo 7'de verilmiştir.

Tablo 7

Video Oyunların Oynandığı Cihazlar

\begin{tabular}{llll}
\hline Cihaz $^{*}$ & Cihaz Alt Türï & Alt toplam & Toplam \\
\hline Video oyun konsolu & $\begin{array}{l}\text { Nintendo } \\
\text { (Wii/Gamecube/Switch) }\end{array}$ & 13 & 39 \\
& $\begin{array}{l}\text { Microsoft Xbox } \\
\text { Sony PlayStation }\end{array}$ & 14 & \\
Kişisel masaüstü bilgisayar (PC) & 12 & 16 \\
Akıllı telefon & Android & 9 & 13 \\
Tablet & iOS & 4 & 10 \\
& Android Tabletler & 5 & \\
Akallı televizyon & iPad & 3 & 1 \\
Belirtilmemiş & BlackBerry PlayBook & 2 & 29 \\
\hline
\end{tabular}

${ }^{\star}$ Bazı oyunlar birden fazla cihazda oynanabilmektedir.

${ }^{\star *}$ Bu tabloda cihazların sürümleriyle ilgili bilgi verilmemiştir.

Tablo 7'de video oyunların oynandığı teknolojik cihazlara yer verilmektedir. Video oyun konsolları (f=39) bu konuda en çok kullanılan aygıtlar olarak dikkat çekmektedir. Video oyun konsollarında ise Microsoft firmasının ürettiği Xbox ( $\mathrm{f}=14)$ konsolları en yoğun kullanılan cihaz olarak görülmektedir. Video oyun konsollarından sonra kişisel masaüstü bilgisayarların ( $\mathrm{f}=16)$ hala en çok kullanılan teknolojik cihazlar olduğu anlaşılmaktadır. Toplam 13 makalede video oyunlar akıllı telefon kullanılarak oynanmaktadır. Dokuz makalede Android işletim sistemi kullanılırken, dört makalede ise iOS işletim sistemi kullanılmıştır. Tabletler de akıllı telefonlar gibi sık kullanılan mobil oyun cihazlarıdır. Toplam 10 araştırmada teknolojik ortam olarak tabletler kullanılırken, Android Tabletler $(\mathrm{f}=5)$, iPad $(\mathrm{f}=3)$ ve BlackBerry PlayBook $(\mathrm{f}=2$ ) araştırmalar gerçekleştirilirken kullanılan diğer mobil cihazlar olarak sıralanmaktadır. Bir araştırmada ise akıllı televizyonlardan Samsung Smart Tv bir oyun ortamı olarak kullanılmıştır.

\section{Video Oyunların Oynandığı Fiziksel Ortamlar}

Video oyunların oynandığı fiziksel ortamlar ile ilgili bilgiler Tablo 8'de verilmiştir. 
Tablo 8

Video Oyunların Oynandığı Fiziksel Ortamlar

\begin{tabular}{ll}
\hline Ortam & f \\
Sinıf & 23 \\
Bilgisayar laboratuarı & 10 \\
Fen laboratuarı & 5 \\
Ev & 5 \\
Ameliyathane & 1 \\
Topluluk Merkezi & 1 \\
Ofis & 1 \\
Kütüphane & 1 \\
Belirtilmemiş & 20 \\
Toplam & 67 \\
\hline
\end{tabular}

Tablo 8'de araştırmalarda video oyunların oynandığı fiziksel ortamlar yer almaktadır. Fiziksel ortamlar olarak video oyun uygulamalarının en çok sınıflarda $(\mathrm{f}=23)$ gerçekleştirildiği görülmektedir. Bu ortamı, bilgisayar laboratuarları $(\mathrm{f}=10)$ takip etmektedir. Fen laboratuarları ve evlerde de 5'er uygulamanın gerçekleştirildiği anlaşılmaktadır. Ameliyathane, topluluk merkezi, ofis ve kütüphane $(\mathrm{f}=1)$ oyunların oynandığı diğer fiziksel ortamlar olarak tabloda gösterilmektedir.

\section{Araştırmalarda Kullanılan Yöntemler}

Araştırmalarda kullanılan yöntemler ile ilgili bilgiler Tablo 9'da verilmiştir.

Tablo 9

Araştırmalarda Kullanılan Yöntemler

\begin{tabular}{ll}
\hline Yöntem & f \\
\hline Nicel & 31 \\
Karma & 12 \\
Nitel & 10 \\
Kuramsal & 5 \\
Tasarım tabanlı & 4 \\
Tarama (Review) & 4 \\
Belirtilmemiş & 1 \\
Toplam & 67 \\
\hline
\end{tabular}

Tablo 9'da araştırmalarda kullanılan yöntemler listelenmektedir. Buna göre, en çok nicel yöntemlerin ( $\mathrm{f}=31$ ) tercih edildiği; bunu karma $(\mathrm{f}=12)$ ve nitel $(\mathrm{f}=10)$ yöntemlerin izlediği görülmektedir. Yalnızca kuramsal çerçeve üzerine inşa edilen ( $\mathrm{f}=5)$, tasarım tabanlı $(\mathrm{f}=4)$, tarama (review) $(\mathrm{f}=4)$ çalışmalar da gerçekleştirilmiştir.

\section{Araştırmalarda Kullanılan Veri Toplama Araçları}

Araştırmalarda kullanılan veri toplama araçları ile ilgili bilgiler Tablo 10'da verilmiştir. 
Tablo 10

Araştırmalarda Kullanılan Veri Toplama Araçları

\begin{tabular}{ll}
\hline Veri Toplama Aracı & f \\
\hline Başarı testi & 32 \\
Anket & 26 \\
Görüşme & 21 \\
Ölçek & 10 \\
Gözlem & 9 \\
Dökümanlar & 7 \\
Odak grup & 2 \\
Çevrimiçi blog gönderileri & 2 \\
Delphi panelleri & 2 \\
Kavram haritaları & 1 \\
Oylama araçları (polls) & 1 \\
Kisa raporlar & 1 \\
Mesajlar & 1 \\
Proje verileri & 1 \\
Kart derecelendirme & 1 \\
Alan notları & 1 \\
Belirtilmemiş & 4 \\
$*$ Bazı çalı̧malarda birden fazla veri toplama aracı kullanılmıştır.
\end{tabular}

Tablo 10'da araştırmalarda kullanılan veri toplama araçlarının bir listesi bulunmaktadır. Buna göre, veri toplama araçlarında en çok başarı testi $(\mathrm{f}=32)$ kullanılırken, bu aracı anket $(\mathrm{f}=26)$ izlemektedir. 21 araştırmada görüşme yapılırken, 10 araştırmada ölçeklerden yararlanılmıştır. Gözlem dokuz, dökümanlar yedi, odak grup iki, çevrimiçi blog gönderileri iki, delphi panelleri iki araştırmada veri toplama aracı olarak kullanılmıştır.

\section{Araştırmalarda Yer Alan Örneklem Grubu}

Araştırmalarda yer alan örneklem grubu ile ilgili bilgiler Tablo 11'de verilmiştir.

Tablo 11

Araştırmalarda Yer Alan Örneklem Grubu

\begin{tabular}{ll}
\hline Örneklem Grubu & f \\
\hline İlköğretim öğrencileri & 25 \\
Lisans öğrencileri & 15 \\
Öğretmenler & 6 \\
Lise öğrencileri & 5 \\
Oyuncular & 3 \\
Ebeveynler & 2 \\
Üniversite öğretim elemanları & 2 \\
Lisansüstü öğrenciler & 1 \\
Oyun geliştiriciler & 1 \\
Oyun yayınlayıcılar & 1 \\
Tıp fakültesi cerrahi asistanları & 1 \\
Alan uzmanları & 1 \\
Hastalar & 1 \\
Yaşlılar (60 yaş üstü) & 1 \\
Belirtilmemiş & 9 \\
\hline${ }^{* B a z ı ~ c ̧ a l ı s ̦ m a l a r d a ~ b i r d e n ~ f a z l a ~ o ̈ r n e k l e m ~ g r u b u ~ k u l l a n ı l m ı s t ı r . ~}$
\end{tabular}


Tablo 11'de araştırmalarda yer alan örneklem grupları görülmektedir. Buna göre, 25 araştırma ile en fazla örneklem olarak hedeflenen grup ilköğretim öğrencileridir. Onları 15 araştırmada kullanılan lisans öğrencileri takip etmektedir. Öğretmenler 6, lise öğrencileri 5, oyuncular 3, ebeveynler 2 ve üniversite öğretim elemanları 2 araştırma ile izlemektedir. Lisansüstü öğrenciler, oyun geliştiriciler, oyun yayınlayıcılar, tıp fakültesi cerrahi asistanları, alan uzmanları, hastalar ve 60 yaş üstü yaşlılar birer araştırmada örneklem grupları içerisinde yer almaktadır.

\section{Araştırmalarda Kullanılan Örneklem Sayısı}

Araştırmalarda kullanılan örneklem sayısı ile ilgili bilgiler Tablo 12'de verilmiştir.

Tablo 12

\begin{tabular}{ll}
\multicolumn{2}{l}{ Araştırmalarda Kullanılan Örneklem Sayıs1 } \\
\hline Örneklem Büyüklüğ̈̈ & f \\
\hline $0-50$ & 14 \\
$51-100$ & 13 \\
$101-200$ & 13 \\
$201-300$ & 2 \\
$301-400$ & 4 \\
$401-500$ & 2 \\
$501-1000$ & 4 \\
$1001+$ & 2 \\
Belirtilmemiş & 13 \\
Toplam & 67
\end{tabular}

Tablo 12'de araştırmalarda kullanılan örneklem sayısı ile ilgili bilgiler verilmektedir. Bu tabloya göre, 0-50 arasındaki örneklem sayısı ( $\mathrm{f}=14$ ) en çok tercih edilen örneklem sayısıdır. 13'er makalede 51-100 ve 101-200 arası örneklem kullanılmıştır. 2 çalışmada 201-300, 4 çalışmada 301-400, 2 çalışmada 401-500, 4 çalışmada ise 501-1000 arası örneklemden veri toplanmıştır. 2 çalışmada ise 1001 ve daha fazla sayıda örneklem yer almıştır.

\section{Araştırmalarda Kullanılan Kuramlar/Yaklaşımlar/Modeller}

Araştırmalarda kullanılan kuramlar/yaklaşımlar/modeller ile ilgili bilgiler Tablo 13’te verilmiştir. 
Tablo 13

Araştırmalarda kullanılan kuramlar/yaklaşımlar/modeller

\begin{tabular}{|c|c|}
\hline Kuram/Yaklaşım/Model Adı & f \\
\hline Oyun Tabanlı Öğrenme & 17 \\
\hline Teknoloji Kabul Modeli & 3 \\
\hline Öğrenmede Evrensel Tasarım İlkeleri & 3 \\
\hline Yapılandırmacı Öğrenme Kuramı & 2 \\
\hline ARCS Motivasyon Modeli & 2 \\
\hline Sorgulamaya Dayalı Öğrenme Modeli & 2 \\
\hline Bağlantılı Öğrenme Çerçevesi & 1 \\
\hline Carroll's Zekâ Modeli & 1 \\
\hline Bilişsel Gelişim Kuramı & 1 \\
\hline Bilișsel Ayar Kuramı & 1 \\
\hline Uygulama Topluluğu & 1 \\
\hline Durumlu Öğrenme Kuramı & 1 \\
\hline Yapılandırılabilir Özgün Temsiller Tasarım Prensibi & 1 \\
\hline “Düşünülmesi Gereken Nesneler” Prensibi & 1 \\
\hline Aktif Öğrenme Kuramı & 1 \\
\hline Etik Uygulama ve Uygulama Sınıflandırma Çerçevesi & 1 \\
\hline Beklenti-Değer Kuramı & 1 \\
\hline Ters Yüz Edilmiş Öğrenme & 1 \\
\hline Genel Duyușsal Saldırganlık Modeli & 1 \\
\hline Oyun Akıșı Kuramı & 1 \\
\hline Oyun Transferi Olguları & 1 \\
\hline Bireysel ADAPTabilite Kuramı & 1 \\
\hline Genel Beceri Teorisi & 1 \\
\hline Teknolojik Pedagojik İçerik Bilgisi & 1 \\
\hline Sosyal Bilişsel Kuram & 1 \\
\hline Mayer'in Multimedya Öğreniminde Bilişsel Kuramı & 1 \\
\hline Çoklu Zekâ Kuramı & 1 \\
\hline Uygulamaya Dayalı Öğrenme & 1 \\
\hline Sistem Tabanlı Uygulama Yaklaşımı & 1 \\
\hline Okulda Öğrenme Yaklaşımı & 1 \\
\hline Sosyal Yapılandirmacı Kuram & 1 \\
\hline Belirtilmemiş & 33 \\
\hline
\end{tabular}

Tablo 13'te araştırmalarda kullanılan kuramlar/yaklaşımlar/modeller sıralanmaktadır. Buna göre, oyun tabanlı öğrenmenin araştırmalarda en çok kullanılan kuramsal yaklaşım olması $(\mathrm{f}=17)$ doğal bir bulgu olarak görülebilir. Teknoloji Kabul Modeli ( $\mathrm{f}=3$ ), Öğrenmede Evrensel Tasarım İlkeleri $(\mathrm{f}=3$ ), Yapılandırmacı Öğrenme Kuramı ( $\mathrm{f}=2)$, ARCS Motivasyon Modeli ( $\mathrm{f}=2)$, Sorgulamaya Dayalı Öğrenme Modeli $(\mathrm{f}=2)$ diğer popüler kuram model ve yaklaşımlar olarak dikkat çekmektedir.

\section{Diğer Web of Science Bulguları}

$\mathrm{Bu}$ sistematik taramada elde edilen bulgular dışında Web of Science veritabanında yapılan aramaların sistem tarafından hazır olarak analiz edildiği bazı bulguları paylaşmanın da çalışmada elde edilen bulgulara destek vereceği ve zenginleştireceği düşünülmektedir. Web of Science'ta otomatik olarak oluşturulan analiz bilgilerine göre, bu konudaki araştırmaların en çok ABD'li araştırmacılar tarafından gerçekleştirildiği ( $f=34)$, bu ülkeyi İspanya ( $\mathrm{f}=6$ ) ve Tayvan'ın ( $\mathrm{f}=4)$ takip ettiği görülmektedir. Araştırmaların gerçekleştirildiği üniversitelerin analizi incelendiğinde ise, State University System of Florida, University of Central Florida ve University of 
North Carolina'da 4'er adet araştırmanın yapıldığı ve üniversite bazında en yüksek sayıya ulaşıldığı anlaşılmaktadır. Yazarlar bazında yapılan incelemede bu konuda yapılan en çok araştırmanın Matthew T. Marino ( $\mathrm{f}=4$ ) tarafından gerçekleştirildiği gözlenmektedir.

\section{Sonuç, Tartışma ve Öneriler}

Bu araştırmada, 2007-2019 yılları arasında, başlı̆̆ında "video games" sözcükleri olan, Web of Science veritabanındaki SSCI indexli dergilerde yayınlanan 67 makale sistematik tarama yöntemiyle incelenmiş ve eğitim araştırmalarında kullanılan video oyunlarıyla ilgili eğilimler belirlenmiştir. Bu çalışmada video oyunlarının eğitim alanındaki kullanımına yönelik olarak gerçekleştirilen araştırmaların en çok Computers \& Education dergisinde yayınlandığı görülmektedir. Q1 çeyrekliğinde olan ve eğitim/eğitim araştırmaları kategorisinde 243 dergi içerisinde 3. sırada olan bu dergide 8 makale yayınlanmıştır. Eğitim ve e-öğrenme alanında saygın bu dergi dışında, 6 makale Journal of Science Education and Technology'de, 4 makale ise British Journal of Educational Technology adlı dergide yayınlanmıştır. Educational Technology ve Society dergisinde 3 ve Theory into Practice dergisinde 3 makalenin yayınlandı̆̆ı görülmektedir. Makalelerin yayınlandığı bu dergilerin hem etki faktörleri, hem de çeyrek kategorisi anlamında üst düzey dergiler olması dikkat çekicidir. Yapılan çalışmalarda genellikle sistematik tarama yapılan veritabanları ve indeks bilgilerinin makalede verildiği ancak dergilerle ilgili bilgilerin çok fazla sunulmadığı gözlenmiştir. Çoban, Yılmaz, Yılmaz ve Göktaş (2016), üç boyutlu oyunların eğitimde kullanılmasıyla ilgili yaptıkları çalışmada ve Hung, Yang ve Tsai (2020) bir okuryazarlık uygulaması olarak öğrenci oyun tasarımıyla ilgili 2010-2020 arası 10 yıllık periyodu taradığı çalışmasında dergi bilgilerine yer vermiştir. Bu iki çalışmada da en çok makalenin Computers \& Education dergisinde yer alması bu çalışmadaki bulguyu destekler niteliktedir.

Eğitim alanında video oyunların işlendiği makalelerin yıllara göre değişimi incelendiğinde 2011-2015 yılları arasındaki yükselişin, 2016 yılında hızlı bir düşüş geçirdiği ve bu düşüşün ardından 2017 yılında zirveye ulaşıldığı görülmektedir. Bu durum Statista (2021) verilerinde de 2017 yllından sonra dünya genelindeki oyuncu sayısının hızla artması ve video oyunlarının popülerleşmesiyle ilişkili olabilir. Verilere göre, 2017 yılındaki video oyuncu sayıs1 2.26 milyar iken, 2018'de 2.42 milyara, 2019' da 2.55 milyara, 2020'de 2.69 milyara yükseleceği öngörülmektedir. Geleceğe yönelik olarak video oyuncu sayısının 2021 yılında 2.81 milyara ve 2023 yılında ise 3.07 milyara yükseleceği tahmin edilmektedir. Ayrıca, Cruz, Hanus ve Fox (2017), Holbert ve Wilensky (2019) ile Ward (2018)'da eğitsel video oyunlarının son yıllarda popülerliğinin arttığını belirtmektedirler. Bu makalede de 2018 yılında bir düşüş olsa da, yıllar geçtikçe araştırmalarda video oyunlarına daha fazla yer verildiği görülmektedir. Dünya genelindeki oyuncu sayılarının artması da eğitim araştırmacılarının bu alana daha fazla yönelmesine neden olmuş olabilir.

Video oyunların eğitsel alanları incelendiğinde, 14 makaleyle en çok Fen Bilimleri alanında, ardından 6 makaleyle Matematik ve 4 makaleyle Tıp Eğitimi alanında araştırmaların gerçekleştirildiği bulgusuna ulaşılmıştır. Çoban ve diğerleri (2016), 3 boyutlu oyunlarla ilgili gerçekleştirdikleri içerik analizinde Sosyal Bilimler ve Fen Bilimleri alanı olarak 2 boyutta incelemiş ve bu çalışmanın aksine Sosyal Bilimlerde daha fazla araştırmanın yapıldığını belirtmişlerdir. Bunun nedeni bu iki çalışmanın farklı oyun türlerini incelemiş olmaları olabilir. Boyle ve diğerleri (2016) 2009-2014 yıllarını içeren sistematik tarama araştırmasında, bu çalışmadaki Fen Bilimleri, Matematik ve Tıp sonucuna benzer olarak Bilim, Teknoloji, Mühendislik ve Matematik (STEM) konuları için oyunların en popüler disiplinler olduğu ve bunu 23 makaleyle Tıp alanının takip ettiğini belirtmektedir. 24 STEM oyunundan 12'sinin Fen Bilimleri alanında gerçekleştirildiğini raporlamışlardır. Connolly, Boyle, MacArthur, Hainey ve Boyle (2012) ise 2004-2009 yıllarını kapsayan araştırmasında, bu çalışmalardan farklı olarak "eğlenceyi” bir disiplin olarak sunarak en fazla bu alanda eğitsel video oyun araştırmalarının gerçekleştirildiğini, Sağlık, Sosyal Meseleler ve Fen Bilimlerinin takip ettiğini 
belirtmişlerdir. Benzerlikler olsa da bu çalışmadaki bulgularla genel anlamda örtüşmediği gözlenmektedir. Clark, Tanner-Smith ve Killingsworth (2016) ise, 2000-2012 yllları arasında gerçekleştirilen sistematik tarama ve meta analiz çalışmasında dijital oyunların en fazla Psikoloji disiplininde yer bulduğunu belirtmiş ve bu çalışmadaki bulguyla ters bir sonuç elde edilmiştir. Bu alanı Matematik, Okuryazarlık ve Fen Bilimleri takip etmektedir.

Video oyunlarından elde edilen öğrenme çıtılarında Connolly ve diğerlerinin (2012) sınıflandırması kullanılmıştır. Connolly ve diğerleri (2012) tarafından 2004-2009 yıllarını içeren sistematik alanyazın çalışmasında makalelerin en fazla duyuşsal ve motivasyonel çıtılar içerdiği bulgusuyla bu çalışmadan elde edilen bulgular birbirini desteklemektedir. Ancak bu bulguyu takip eden çıktılar incelendiğinde, bilgi edinme / içerik anlama ve algısal / bilişsel çıktıların yerlerinin değişiklik gösterdiği gözlenmektedir. 4. sıradaki bulgu olan davranış değişikliği ise 2 çalışmada da aynı sırada yer almıştır. Boyle ve diğerleri (2016) tarafından 20092014 yılları arasında gerçekleştirilen sistematik alanyazın taraması çalışmasında ise, motivasyon çıkarılarak yalnızca duyuşsal çıtılara yer verilmiş ve Connolly ve diğerleri (2012) sınıflamasına benzer bir yapı oluşturulmuştur. Bilgi edinme Boyle ve diğerleri (2016) tarafından yapılan çalışmada elde edilen en yüksek çıktı olarak görülmektedir. Bu çalışmada elde edilen bulguyla farklı bir bulgunun elde edildiği anlaşılmaktadır. Boyle ve diğerleri (2016) tarafından yapılan çalışmada diğer en yüksek öğrenme çıktılarının "Algısal ve Bilişsel" ve "Duyuşsal" çıktılar olduğu raporlanmıştır. Papastergiou (2009) tarafından 2000- 2008 yılları arasında sağlık ve beden eğitimi alanında gerçekleştirilen alanyazın taramasında video oyunların bilgi, tutum, davranış, motor becerilerini ve fiziksel egzersiz motivasyonunu artırdığını gösteren çalışmalar bulunduğunu belirtmiştir. Çoban ve diğerleri (2016) ise 3 boyutlu oyunlarla ilgili araştırmalarda daha çok motivasyon veya öğrenme temelli araştırmaların yer aldığına dikkat çekmiştir. Bu çalışmada da benzer şekilde duyuşsal ve özellikle motivasyonel açıdan video oyunların etkisini inceleyen çalışmaların yüksek sayıda olduğu sonucuna ulaşılmıştır.

$\mathrm{Bu}$ araştırmadan önce video oyunlarıyla ilgili gerçekleştirilen sistematik tarama veya içerik analizi çalışmalarında oyunların adları belirtilse de (Graafland, Schraagen ve Schijven, 2012; Zeng ve diğerleri, 2017) bu çalışmadakine benzer şekilde eğitim araştırmalarında video oyunların adlarını belirten herhangi bir çalışmaya rastlanmamıştır. $\mathrm{Bu}$ çalışmada yapılan sistematik taramada eğitim araştırmalarında en çok kullanılan video oyunun "You Make Me Sick!" olduğu sonucuna ulaşılmıştır (Israel ve diğerleri, 2016; Marino ve diğerleri, 2013; Marino ve diğerleri, 2014). You Make Me Sick! bakteri, virüs ve diğer bulaşıcı hastalıkların öğretiminde kullanılan Fen Bilimleri Biyoloji oyunudur. Öğrencilerin kendi virüslerini veya bakterilerini tasarlamalarını, konakçıları enfekte etmelerini ve hastalıklarını uzaklara yayabilmelerini sağlamaktadır.

Video oyun türleriyle ilgili farklı araştırmacıların farklı sınıflandırmalar (Boyle ve diğerleri, 2016; Connolly ve diğerleri, 2012; Graafland, Schraagen, ve Schijven, 2012; Kron ve diğerleri, 2010; Phan ve Tan, 2017) kullandığ1 görülebilmektedir. Video oyunların türleri incelendiğinde eğitim araştırmalarında eğitsel ve ciddi oyunların en yoğun olarak kullanılması doğal bir bulgu olarak düşünülebilir. Ancak bu oyunlar dışında da eğitim ortamlarında farklı oyun türlerinden yararlanıldığı sonucuna ulaşılmıştır. Örneğin, aksiyon-macera türü oyunlar özellikle de gerçek zamanlı 3B macera oyunları araştırmalarda kullanılmıştır. Bunların dışında, rol oynama oyunları da bir diğer popüler oyun türüdür. Bu oyun türünde kitlesel çok oyunculu çevrimiçi rol oynama oyunları ve korumalı alan oyunları da tercih edilen oyun türlerindendir. Alanda yapılan sistematik tarama çalışmalarında da, Connolly ve diğerleri (2012) tarafından yapılan araştırmada 2004-2009 yılları arasında simülasyon türü oyunların toplam 43 makaleyle ilk sırada yer bulduğu görülmektedir. Bu türü takip eden jenerik oyunlar 22 makale ile 2. sıradayken, 3. sırada 14 makale ile aksiyon oyunları yer almaktadır. Boyle ve diğerleri (2016), Connolly ve diğerleri (2012) araştırmasına benzer olarak bilgisayar ve eğitsel oyunların en çok simülasyon türü oyunlardan oluştuğu, daha sonra ise rol oynama oyunlarının, tatbikat oyunlarının, 
Kitlesel çok oyunculu çevrimiçi rol oynama oyunlarının, strateji oyunlarının, eşleme bulmaca ve macera oyunlarının takip ettiğini raporlamışlardır. Bu iki çalışmada elde edilen oyun türü bulgularının, bu sistematik taramadaki bulgularla örtüşmediği sonucuna ulaşılmıştır. Bu çalışmalardaki bulgularla mevcut araştırmanın farklı sonuçlar içermesinin nedenleri, hem incelenen veritabanı ve indekslerin, hem de incelenen yılların farklı olması olabilir. Ayrıca, bu çalışmalardaki oyun türü sınıflandırmasının da farklı olduğu görülmektedir.

Video oyunların oynandığı teknolojik cihazlara bakıldığında yapılan sistematik taramada en çok video oyun konsollarının kullanıldığı ve Microsoft Xbox’ın en çok tercih edilen video konsolu olduğu tespit edilmiştir. Onu Nintendo ve Sony PlayStation takip etmektedir. Video oyun konsollarını, kişisel bilgisayarlar, akıllı telefonlar, tabletler ve akıllı televizyonlar takip etmektedir. ISFE (2019) raporlarına göre, Avrupa pazarının 2018 yllında \%47'sini video oyun konsollarının gelirleri oluştururken, \%34'ün mobil/tablet gelirlerinden ve \%18'in kişisel bilgisayar gelirlerinden ve \%2'nin el bilgisayarları gelirlerinden oluştuğu görülmektedir. Söz konusu raporda bu çalışmada elde edilen bulguyu destekler nitelikte video oyun konsolları ön plana çıkmaktadır. Statista (2019a) raporlarında, video oyun konsollarının liderlik pozisyonunda Sony, Microsoft ve Nintendo'nun olduğunu ve Sony'nin PlayStation 4 konsolunun mevcut nesil konsollar arasında en çok satan ürün olduğu gösterilmektedir. Ancak aynı raporda, 2019 yılında video oyun konsollarının satışlarının azalmaya başladığını belirtmesi de dikkat çekicidir. Martin-Gutierrez ve diğerlerine (2009) göre, video oyunu kullanıcıları arasında en yaygın kullanılan platformlar, kişisel bilgisayar, Sony PlayStation, Sony PlayStation Portable (PSP), Nintendo Wii, Nintendo DS, Nintendo Game Boy Advance ve Microsoft Xbox 360 olarak sıralanmaktadır. Oyuncular tarafından daha az kullanılan diğer platformları ise Nintendo Game Cube, Sega Dreamcast, Nokia N-Gage, Game Park 32 olarak raporlamışlardır. Haaranen ve diğerleri (2014), dijital ve video oyunlarının sağlık davranışları üzerindeki etkileri üzerinde gerçekleştirdikleri sistematik taramada, en çok kullanılan video oyun konsolunun Nintendo Wii olduğunu, bunu Sony PlayStation, Microsoft Xbox veya Xavix olduğunu belirlemişlerdir. Connolly ve diğerleri (2012) yaptığı sistematik alanyazın taramasında, en çok (73) kişisel bilgisayarların kullanıldığı, onu video konsollarının (28) takip ettiğini ortaya koymuşlardır. Boyle ve diğerleri (2016) ise, buna benzer olarak kişisel ve dizüstü bilgisayarların en yoğun kullanılan cihazlar olduğunu ve mobil cihazlarda oynanan oyunların sayısının yalnızca 2 olduğunu belirtmişlerdir.

Video oyunların oynandığı fiziksel ortamlara bakıldığında, bu konuda yapılıış sistematik tarama veya içerik analizi çalışmalarında bu bileşenin hiç incelenmediği ve bu çalışmada elde edilen bulguların özgün bulgu niteliği taşıdığı söylenebilir. Video oyun uygulamalarının en çok sınıflarda, bilgisayar laboratuarlarında, fen laboratuarlarında ve evlerde gerçekleştirildiği görülmektedir. Bunun dışında ameliyathane, topluluk merkezi, ofis ve kütüphanelerde de video oyunların oynandığı eğitim araştırmalarının olması dikkat çekici bir sonuçtur.

Eğitimde video oyunlarla ilişkili çalışmalarda kullanılan yöntemlere bakıldığında en yüksek nicel, daha sonra ise karma, nitel, kuramsal, tasarım tabanlı ve tarama araştırmaların izlediği görülmektedir. Boyle ve diğerleri (2016) yaptığı çalışmada kullanılan sınıflandırma farklı olsa da yarı deneysel 72 çalışmanın gerçekleştirilmiş olmasıyla nicel yöntemlerin ağırlıklı olarak kullanıldığı sonucuna ulaşılabilir. Daha sonra 27 makalede anket, 21 çalışmada korelasyon yöntemlerinin kullanıldığını belirtilmiştir. Yalnızca 5 çalışmada nitel araştırma yöntemi kullanıldığı tespit edilmiştir. Connolly ve diğerleri (2012) ise benzer şekilde gerçekleştirilen sistematik alanyazın taramasında yarı deneysel (65) yöntemin en yoğun kullanıldığını, bunu anketin (43) takip ettiğini, nitel çalışmaların ise, yalnızca 8 makalede tercih edildiği sonucuna ulaşmışlardır. Hem Boyle ve diğerleri (2016), hem de Connolly ve diğerleri (2012) çalışmalarında elde edilen bu bulguların bu çalışmadaki bulgularla benzerlik taşıdığı ve birbirini desteklediği görülmektedir.

Araştırmalarda kullanılan veri toplama araçlarılya ilgili herhangi bir sistemik tarama ve benzer analiz çalışmalarına ulaşılamamıştır. Bu çalışmada en çok kullanılan veri toplama araçları olarak test, anket, görüşme, 
ölçek, gözlem, dökümanlar, odak grup, çevrimiçi blog gönderileri, delphi panelleri, kavram haritaları, oylama araçları, kısa raporlar, mesajlar, proje verileri, kart derecelendirme ve alan notları saptanmıştır. Bu çalışmada elde edilen bu bulgular çalışmanın özgün niteliğini ortaya koymaktadır.

Araştırmalarda yer alan örneklem grupları incelendiğinde, en fazla örneklem olarak hedeflenen grubun ilköğretim öğrencileri olduğu tespit edilmiştir. Çoban ve diğerleri (2016) 3B oyunların araştırmalarıyla ilgili yaptıkları içerik analizinde benzer bir sonuç elde ederek \%29'luk kitlenin ilköğretim düzeyinde olduğunu, bu kişilerin yaş ortalamalarının yaklaşık olarak 14-15 yaş arasında değiştiğini ve yetişkinlerin öğrenme sürecinde oyunlardan daha az yararlandığını belirtmişlerdir. ISFE (2019) Avrupa temelinde yayınladıkları raporda, 1114 yaş arasındaki erkek bireylerin video oyunlarını oynamayı daha çok tercih ettiklerini göstermişlerdir. İlköğretim öğrencileri dışında, lisans öğrencileri, öğretmenler ve lise öğrencileri de örneklem grubu olarak en çok seçilen gruplar olarak dikkat çekmektedir.

Eğitim araştırmalarında video oyunların kullanımıyla ilgili kullanılan örneklem sayılarıla ilgili bundan önce incelenen çalışmalarda herhangi bir bilgiye yer verilmediği görülmektedir. Yalnızca Sánchez-Mena ve MartíParreño (2017) tarafından öğretmenlerin eğitsel oyunları kabulüne ilişkin gerçekleştirilen bir kapsamlı alanyazın taramasında bazı bilgilere yer verilse de bağlamsal açıdan farklı çalışmalar olduğu yargısına ulaşılmıştır. Sánchez-Mena ve Martí-Parreño'nun (2017) çalışmasında yalnızca öğretmenlerin örneklem grubu olarak seçilmiş olması ve örneklem büyüklügüne ilişkin analizlerin ilgili aralık yerine doğrudan sayısal olarak tabloda gösterilmiş olması bakımından bu çalışma ile aynı düzlemde değerlendirilmemiştir. Bu çalışmada elde edilen bulgulara göre, 0-50 arası (Garneli ve Chorianopoulos, 2018; Holbert ve Wilensky, 2019; Ouariachi ve diğerleri, 2019) kullanılan örneklem sayısının en çok tercih edildiği görülmektedir. Çalışmalarda küçük örneklem gruplarının seçilmesi ve 1000'den fazla sayıda örneklem seçilen yalnızca 2 çalışmanın olması dikkat çekici bir sonuçtur.

Eğitimde video oyunları konu alan araştırmalarda kullanılan kuramlar/yaklaşımlar/modellerle ilgili bu çalışmadan önceki analizlere bakıldığında Çoban ve diğerleri (2016) tarafından 3B oyunların eğitimde kullanılmasına yönelik gerçekleştirilen içerik analizi çalışması ve Papastergiou (2009) tarafından gerçekleştirilen video oyunların sağlık ve beden eğitimde kullanılmasını içeren literatür tarama çalışmaları yer almaktadır. Papastergiou (2009) göre, oyunları kategorilendirirken, "Gelişme”, “Tartışma” ve “Teori” olarak 3 kategori kullanmış ve 3 makalenin teorik makale olduğunu belirtmiştir. Ancak hangi teori veya yaklaşım olduğunu belirtmemiştir. Çoban ve diğerlerine (2016) göre ise, oyunların eğitimde kullanım sürecinde; öğrenme teorileri yaklaşımları ya da yöntemlerinden yeterince yararlanılmadığı ancak bazı çalışmalarda; deneyimsel öğrenme ve çoklu zekâ kuramı, oyun ve rol temelli öğrenme, sosyokültürel ve grupla öğrenme gibi kuram ve yaklaşımların kullanıldığını belirtmektedir. Bu çalışmada video oyun çalışmalarında en çok Oyun Tabanlı Öğrenme, Teknoloji Kabul Modeli ve Öğrenmede Evrensel Tasarım İlkelerinin kullanıldığı görülmektedir.

$\mathrm{Bu}$ araştırmanın bulguları doğrultusunda bazı öneriler sunulabilir. Eğitimde video oyunları içeren araştırmalar incelendiğinde, duyuşsal ve motivasyonel araştırmaların yoğunluğu dikkat çekmektedir. Video oyunları oynamada motor becerileri, sosyal / yumuşak beceriler ve fizyolojik incelemelerin önemli rol oynadığı düşünüldüğünde bu becerilere ve öğrenme çıtılarına ağırlık verilmesi önerilebilir. Video oyunların oynandığı cihazlarda video oyun konsollarının yoğunlukla kullanıldığı görülmektedir. Bu doğal bir bulgu olsa da, bu noktada özellikle akıllı telefonların popülerleşmesiyle birlikte bu mobil cihazların kişisel bilgisayarlara göre daha yoğun kullanılması gerektiği söylenebilir. Ayrıca, tablet ve akıllı televizyonların da video oyun cihazları olarak daha fazla kullanılması önerilebilir. Araştırma yöntemleri bağlamında, nitel, kuramsal ve tasarım tabanlı yöntemleri içeren daha fazla çalışma önerilebilir. Ayrıca, veri toplama araçlarında da daha fazla çeşitliliğe 
ihtiyaç duyulduğu anlaşılmaktadır. Yapılan sistematik taramada, daha çok öğrenci ve öğretmenlerin video oyun araştırmalarında örneklem olarak kullanıldığı görülmüştür. Daha farklı örneklem gruplarının da bu tür araştırmalarda kullanılması önerilebilir. Örneklem sayısının da genellikle 0-200 arasında çok fazla yoğunlaştığı; daha büyük örneklem gruplarıyla çalışılması gerektiği söylenebilir. Kuramsal bağlamda, Oyun Tabanlı Öğrenme yaklaşımının yanı sıra, Teknoloji Kabul Modeli, Öğrenmede Evrensel Tasarım İlkeleri ve Teknoloji Kabul Modeli ağırlıklı olarak kullanılmaktadır. Özellikle daha fazla oyun temelli yaklaşımın eğitim araştırmalarında kullanılması önerilebilir.

$\mathrm{Bu}$ araştırmada oyunun adı, oyunun türü, oyunun oynandığı cihazlar, oyunun oynandığ fiziksel ortamlar gibi video oyunlara özel bazı bileşenler sistematik tarama ile incelenmiştir. Bu çalışmada incelenen özellikler dışında, oyun geliştiricilerine, oyun yayıncılarına, oyun tasarımcılarına, oyunun serisine, oyunun oyuncu moduna (tek oyunculu-çok oyunculu), ticari veya ücretsiz olup olmadığı gibi ek özelliklerin analiz edilmesi de önerilebilir. Ayrıca, bu çalışmada kullanılan Web of Science veritabanı yerine, ERIC, Scopus, EBSCO, TR Dizin gibi farklı veritabanları önerilebilir. Yıl periyodu da değiştirilerek daha geniş veya daha dar zaman aralıklarında tarama yapılabilir. Bu çalışmada kullanılan sistematik tarama yerine, bibliyografik analiz, içerik analizi, meta analiz veya meta sentez gibi nicel veya nitel ağırlıklı analiz teknikleri kullanılabilir.

\section{Araştırmanın Sınırlılıkları}

$\mathrm{Bu}$ araştırma bazı sınırlılıklara sahiptir. İlk olarak, bu çalışmada sistematik bir şekilde taranan makaleler yalnızca eğitim bilimleri alanıyla sınırlıdır. Çalışmada makalelerin yayınlandığı yıl periyodu sınırlanarak yalnızca 2007-2019 yılları seçilmiştir. Ayrıca, başlığında yalnızca "video oyun" anahtar sözcüğü kullanılarak, dijital oyunlar, çevrimiçi oyunlar, ciddi oyunlar gibi farklı oyun türleriyle karışıklık yaşanmasının önüne geçilmiştir. Seçilen veritabanı ise Web of Science veritabanıyla sınırlıdır. Web of Science bünyesinde barındırdığı dizinleri ile akademik olarak en saygın veritabanlarından biri olarak kabul edilmektedir. Bu çalışma kapsamında da 1980 yılından beri Sosyal Bilimler alanında en etkili dizinlerden biri olarak kabul edilen SSCI seçilmiştir. Veritabanında arama yapılırken yalnızca başlıklarda arama seçeneği ile sınırlandırılmıştır. Özet, konu (topic) ve anahtar sözcüğe göre yapılan taramalarda ilgisiz araştırmaların da listelenmesinden dolayı, başlığa göre taramanın en sağlıklı seçenek olduğuna karar verilmiştir.

\section{Kaynakça}

Adams, B. J., Margaron, F. ve Kaplan, B. J. (2012). Comparing video games and laparoscopic simulators in the development of laparoscopic skills in surgical residents. Journal of Surgical Education, 69(6), 714-717. doi: $10.1016 /$ j.jsurg.2012.06.006

Barnett, A., Cerin, E., ve Baranowski, T. (2011). Active video games for youth: A systematic review. Journal of Physical Activity and Health, 8(5), 724-737. doi: 10.1123/jpah.8.5.724

Bediou, B., Adams, D. M., Mayer, R. E., Tipton, E., Green, C. S. ve Bavelier, D. (2018). Meta-analysis of action video game impact on perceptual, attentional, and cognitive skills. Psychological Bulletin, 144(1), 77-110. doi: $10.1037 /$ bul0000130

Beserra, V., Nussbaum, M. ve Oteo, M. (2019). On-task and off-task behavior in the classroom: A study on mathematics learning with educational video games. Journal of Educational Computing Research, 56(8), 1361-1383. doi: 10.1177/0735633117744346

Beserra, V., Nussbaum, M., Zeni, R., Rodriguez, W. ve Wurman, G. (2014). Practising arithmetic using educational video games with an interpersonal computer. Journal of Educational Technology ve 
Society, 17(3),

343-358.

Erişim

adresi:

https://www.jstor.org/stable/jeductechsoci.17.3.343?seq=1\#metadata_info_tab_contents

Bonney, E., Jelsma, D., Ferguson, G. ve Smits-Engelsman, B. (2017). Variable training does not lead to better motor learning compared to repetitive training in children with and without DCD when exposed to active video games. Research in Developmental Disabilities, 62, 124-136. doi: 10.1016/j.ridd.2017.01.013

Boyle, E. A., Hainey, T., Connolly, T. M., Gray, G., Earp, J., Ott, M. ... ve Pereira, J. (2016). An update to the systematic literature review of empirical evidence of the impacts and outcomes of computer games and serious games. Computers \& Education, 94, 178-192. doi: 10.1016/j.compedu.2015.11.003

Brand, J. E., Knight, S. ve Majewski, J. (2003). The diverse worlds of computer games: a content analysis of spaces, populations, styles and narratives. DiGRA konferansında sunulan bildiri. Erişim adresi: http://www.digra.org/wp-content/uploads/digital-library/05150.06387.pdf

Bullen, T., Katchabaw, M. J. ve Dyer-Witheford, N. (2006). Automating content analysis of video games. Canadian Game Studies Association (CGSA) Symposium (s. 22-24). Erişim adresi: https://journals.sfu.ca/loading/index.php/loading/article/view/5/2

Caroux, L., Isbister, K., Le Bigot, L. ve Vibert, N. (2015). Player-video game interaction: A systematic review of current concepts. Computers in Human Behavior, 48, 366-381. doi: 10.1016/j.chb.2015.01.066

Ceranoglu, T. A. (2010). Star Wars in psychotherapy: Video games in the office. Academic Psychiatry, 34(3), 233-236. doi: 10.1176/appi.ap.34.3.233

Chen, H. J. H. ve Yang, T. Y. C. (2013). The impact of adventure video games on foreign language learning and the perceptions of learners. Interactive Learning Environments, 21(2), 129-141. doi: $10.1080 / 10494820.2012 .705851$

Clark, D. B., Tanner-Smith, E. E. ve Killingsworth, S. S. (2016). Digital games, design, and learning: A systematic review and meta-analysis. Review of Educational Research, 86(1), 79-122. doi: $10.3102 / 0034654315582065$

Connolly, T. M., Boyle, E. A., MacArthur, E., Hainey, T. ve Boyle, J. M. (2012). A systematic literature review of empirical evidence on computer games and serious games. Computers \& Education, 59(2), 661-686. doi: 10.1016/j.compedu.2012.03.004

Corredor, J., Gaydos, M. ve Squire, K. (2014). Seeing change in time: Video games to teach about temporal change in scientific phenomena. Journal of Science Education and Technology, 23(3), 324-343. doi: 10.1007/s10956-013-9466-4

Cruz, C., Hanus, M. D. ve Fox, J. (2017). The need to achieve: Players' perceptions and uses of extrinsic metagame reward systems for video game consoles. Computers in Human Behavior, 71, 516-524. doi: 10.1016/j.chb.2015.08.017

Çoban, M., Yılmaz, R. M., Yılmaz, T. K. ve Göktaş, Y. (2016). Üç boyutlu oyunların eğitimde kullanılması. Bayburt Eğitim Fakültesi Dergisi, 11(1), 172-187. Erişim adresi: https://dergipark.org.tr/tr/download/article-file/214871

Del Pozo, M. M., Gómez-Pablos, V. B. ve Muñoz-Repiso, A. G. V. (2017). A quantitative approach to preservice primary school teachers' attitudes towards collaborative learning with video games: Previous experience with video games can make the difference. International Journal of Educational Technology in Higher Education, 14(11), 1-18. doi: 10.1186/s41239-017-0050-5

Durkin, K. ve Barber, B. (2002). Not so doomed: Computer game play and positive adolescent development. Journal of Applied Developmental Psychology, 23(4), 373-392. doi: 10.1016/S0193-3973(02)00124-7

Dybå, T. ve Dingsøyr, T. (2008). Empirical studies of agile software development: A systematic review. Information and Software Technology, 50(9-10), 833-859. doi: 10.1016/j.infsof.2008.01.006 
Gallup, J. ve Serianni, B. (2017). Developing friendships and an awareness of emotions using video games: Perceptions of four young adults with autism. Education and Training in Autism and Developmental Disabilities, 52(2), 120-131.

Garneli, V. ve Chorianopoulos, K. (2018). Programming video games and simulations in science education: exploring computational thinking through code analysis. Interactive Learning Environments, 26(3), 386401. doi: $10.1080 / 10494820.2017 .1337036$

Gower, L. ve McDowall, J. (2012). Interactive music video games and children's musical development. British Journal of Music Education, 29(1), 91-105. doi: 10.1017/S0265051711000398

Graafland, M., Schraagen, J. M. ve Schijven, M. P. (2012). Systematic review of serious games for medical education and surgical skills training. British Journal of Surgery,99(10), 1322-1330. doi: $10.1002 / b j s .8819$

Haaranen, A., Rissanen, T., Laatikainen, T. ve Kauhanen, J. (2014). Digital and video games in health promotion: Systematic review of games and health behavior. Finnish Journal of eHealth and eWelfare, 6(4), 153-163.

Hanghøj, T., Lieberoth, A. ve Misfeldt, M. (2018). Can cooperative video games encourage social and motivational inclusion of at-risk students?. British Journal of Educational Technology, 49(4), 775-799. doi: $10.1111 /$ bjet.12642

Hawkins, I., Ratan, R., Blair, D. ve Fordham, J. (2019). The effects of gender role stereotypes in digital learning games on motivation for stem achievement. Journal of Science Education and Technology, 28(6), 628637. doi: 10.1007/s10956-019-09792-w

Holbert, N. ve Wilensky, U. (2019). Designing educational video games to be objects-to-think-with. Journal of the Learning Sciences, 28(1), 32-72. doi: 10.1080/10508406.2018.1487302

Huizinga, J. (1949). Homo ludens: A study of the play-element in culture. London: Routledge ve Kegan Paul.

Hung, H.-T., Yang, J. C. ve Tsai, Y.-C. (2020). Student game design as a literacy practice: A 10-year review. Educational Technology ve Society, 23(1), 50-63. Erişim adresi: https://www.jstor.org/stable/26915406?seq=1\#metadata_info_tab_contents

Hutton, E. ve Sundar, S. S. (2010). Can video games enhance creativity? Effects of emotion generated by Dance Dance Revolution. Creativity Research Journal, 22(3), 294-303. doi: 10.1080/10400419.2010.503540

Ibrahim, K. (2019). Foreign language practice in simulation video games: An analysis of game-based FL use dynamics. Foreign Language Annals, 52(2), 335-357. doi: 10.1111/flan.12388

ISFE. (2019). Europe's video games industry key facts 2019. Erişim adresi: https://www.isfe.eu/wpcontent/uploads/2019/08/ISFE-Key-Facts-Brochure-FINAL.pdf

Israel, M., Wang, S. ve Marino, M. T. (2016). A multilevel analysis of diverse learners playing life science video games: Interactions between game content, learning disability status, reading proficiency, and gender. Journal of Research in Science Teaching, 53(2), 324-345. doi: 10.1002/tea.21273

Kangas, M., Koskinen, A. ve Krokfors, L. (2017). A qualitative literature review of educational games in the classroom: The teacher's pedagogical activities. Teachers and Teaching, 23(4), 451-470. doi: $10.1080 / 13540602.2016 .1206523$

Karaçam, Z. (2014). Sistematik derleme metodolojisi: Sistematik derleme hazırlamak için bir rehber. Dokuz Eylül Üniversitesi Hemşirelik Fakültesi Elektronik Dergisi, 6(1), 26-33. Erişim adresi: https://dergipark.org.tr/tr/download/article-file/753523

Karasar, N. (2006). Bilimsel araştırma yöntemi. Ankara: Nobel Yayın Dağıtım. 
Kenny, R. F. ve McDaniel, R. (2011). The role teachers' expectations and value assessments of video games play in their adopting and integrating them into their classrooms. British Journal of Educational Technology, 42(2), 197-213. doi: 10.1111/j.1467-8535.2009.01007.x

Kron, F. W., Gjerde, C. L., Sen, A. ve Fetters, M. D. (2010). Medical student attitudes toward video games and related new media technologies in medical education. BMC Medical Education, 10(1), 50. doi: $10.1186 / 1472-6920-10-50$

Kuss, D. J. ve Griffiths, M. D. (2012). Internet gaming addiction: A systematic review of empirical research. International Journal of Mental Health and Addiction, 10(2), 278-296. doi: 10.1007/s11469011-9318-5

Lieury, A., Lorant, S., Trosseille, B., Champault, F. ve Vourc'h, R. (2016). Video games vs. reading and school/cognitive performances: A study on 27000 middle school teenagers. Educational Psychology, 36(9), 1560-1595. doi: 10.1080/01443410.2014.923556

Lookadoo, K. L., Bostwick, E. N., Ralston, R., Elizondo, F. J., Wilson, S., Shaw, T. J. ve Jensen, M. L. (2017). “I forgot i wasn't saving the world": The use of formative and summative assessment in instructional video games for undergraduate biology. Journal of Science Education and Technology, 26(6), 597-612. doi: $10.1007 / \mathrm{s} 10956-017-9701-5$

Lu, A. S. ve Kharrazi, H. (2018). A state-of-the-art systematic content analysis of games for health. Games for Health Journal, 7(1), 1-15. doi: 10.1089/g4h.2017.0095

Manero, B., Torrente, J., Serrano, Á., Martínez-Ortiz, I. ve Fernández-Manjón, B. (2015). Can educational video games increase high school students' interest in theatre?. Computers \& Education, 87, 182-191. doi: 10.1016/j.compedu.2015.06.006

Marino, M. T., Gotch, C. M., Israel, M., Vasquez III, E., Basham, J. D. ve Becht, K. (2014). UDL in the middle school science classroom: Can video games and alternative text heighten engagement and learning for students with learning disabilities?.Learning Disability Quarterly, 37(2), 87-99. doi: $10.1177 / 0731948713503963$

Marino, M. T., Israel, M., Beecher, C. C. ve Basham, J. D. (2013). Students' and teachers' perceptions of using video games to enhance science instruction. Journal of Science Education and Technology, 22(5), 667680. doi: 10.1007/s10956-012-9421-9

Martin-Gutierrez, J., Luis Saorin, J., Martin-Dorta, N. ve Contero, M. (2009). Do video games improve spatial abilities of engineering students?. International Journal of Engineering Education, 25(6), 1194-1204. Erişim adresi: https://dialnet.unirioja.es/servlet/articulo?codigo=7416669

Masek, M., Boston, J., Lam, C. P. ve Corcoran, S. (2017). Improving mastery of fractions by blending video games into the Math classroom. Journal of Computer Assisted Learning, 33(5), 486-499. doi: $10.1111 /$ jcal. 12194

Miles, M. B. ve Huberman, A. M. (1994). Qualitative data analysis: An expande sourcebook. CA: Thousand Oaks, Sage.

Moher, D., Shamseer, L., Clarke, M., Ghersi, D., Liberati, A., Petticrew, M. ... ve Stewart, L. A. (2015). Preferred reporting items for systematic review and meta-analysis protocols (PRISMA-P) 2015 statement. Systematic Reviews, 4(1), 1. doi: 10.1186/2046-4053-4-1

Okur, M. ve Aygenc, E. (2017). Video games as teaching and learning tool for environmental and space design. Eurasia Journal of Mathematics, Science and Technology Education, 14(3), 977-985. doi: $10.12973 /$ ejmste/80932

Ouariachi, T., Olvera-Lobo, M. D., Gutiérrez-Pérez, J. ve Maibach, E. (2019). A framework for climate change engagement through video games. Environmental Education Research,25(5), 701-716. doi: $10.1080 / 13504622.2018 .1545156$ 
Palaus, M., Marron, E. M., Viejo-Sobera, R. ve Redolar-Ripoll, D. (2017). Neural basis of video gaming: A systematic review. Frontiers in Human Neuroscience, 11, 248. doi: 10.3389/fnhum.2017.00248

Paney, A. S. (2015). Singing video games may help improve pitch-matching accuracy. Music Education Research, 17(1), 48-56. doi: 10.1080/14613808.2014.969218

Papastergiou, M. (2009). Exploring the potential of computer and video games for health and physical education: A literature review. Computers \& Education, 53(3), 603-622. doi: 10.1016/j.compedu.2009.04.001

Phan, Q. A. ve Tan, V. (2017). Play with bad words: A content analysis of profanity in video games. Acta Ludica-International Journal of Game Studies, 1(1), 7-30. Erişim adresi: https://www.actaludica.com/ojs/index.php/actaludica/article/view/10/4

Piaget, J. (1962). Play, dreams and imitation in childhood. New York: W.W. Norton.

Sánchez-Mena, A. ve Martí-Parreño, J. (2017). Teachers acceptance of educational video games: A comprehensive literature review. Journal of e-Learning and Knowledge Society, 13(2). doi: $10.20368 / 1971-8829 / 1319$

Sánchez-Mena, A., Martí-Parreño, J. ve Aldás-Manzano, J. (2019). Teachers' intention to use educational video games: The moderating role of gender and age. Innovations in Education and Teaching International, 56(3), 318-329. doi: 10.1080/14703297.2018.1433547

Schmierbach, M. (2009). Content analysis of video games: Challenges and potential solutions. Communication Methods and Measures, 3(3), 147-172. doi: 10.1080/19312450802458950

Sezgin, S., Bozkurt, A., Yılmaz, E. A. ve van der Linden, N. (2018). Oyunlaştırma, eğitim ve kuramsal yaklaşımlar: Öğrenme süreçlerinde motivasyon, adanmışlık ve sürdürebilirlik. Mehmet Akif Ersoy Üniversitesi Ĕ̈itim Fakültesi Dergisi, 2018(45), 169-189. doi: 10.21764/maeuefd.339909

Statista (2019a). Video game industry - statistics ve facts. Erişim adresi: https://www.statista.com/topics/868/video-games/

Statista (2019b). Video game market value worldwide from 2012 to 2021. Erişim adresi: https:/www.statista.com/statistics/292056/video-game-market-value-worldwide/

Statista (2020). Video games. Erişim adresi: https://www.statista.com/outlook/203/100/videogames/worldwide\#market-users

Statista (2021). Number of active video gamers worldwide from 2015 to 2023. Erişim adresi: https://www.statista.com/statistics/748044/number-video-gamers-world/

Sun, C. T., Ye, S. H. ve Wang, Y. J. (2015). Effects of commercial video games on cognitive elaboration of physical concepts. Computers \& Education, 88, 169-181. doi: 10.1016/j.compedu.2015.05.002

Ward, M. R. (2018). Cutting class to play video games. Information Economics and Policy, 42, 11-19. doi: 10.1016/j.infoecopol.2017.10.001

Watson, A. M., Alber, J. M., Barnett, T. E., Mercado, R. ve Bernhardt, J. M. (2016). Content analysis of antitobacco videogames: Characteristics, content, and qualities. Games for Health Journal, 5(3), 216-223. doi: $10.1089 / \mathrm{g} 4 \mathrm{~h} .2015 .0096$

Ye, S. H., Hsiao, T. Y. ve Sun, C. T. (2018). Using commercial video games in flipped classrooms to support physical concept construction. Journal of Computer Assisted Learning, 34(5), 602-614. doi: $10.1111 /$ jcal. 12267

You, S., Kim, E. ve No, U. (2015). Impact of violent video games on the social behaviors of adolescents: The mediating role of emotional competence. School Psychology International,36(1), 94-111. doi: $0.1177 / 0143034314562921$ 
Zeng, N., Pope, Z., Lee, J. E. ve Gao, Z. (2017). A systematic review of active video games on rehabilitative outcomes among older patients. Journal of Sport and Health Science, 6(1), 33-43. doi: 10.1016/j.jshs.2016.12.002

\section{Extended Abstract}

\section{Purpose}

The aim of this study is to determine the usage trends of video games in education by analyzing 67 articles in the Social Sciences Citation Index (SSCI) indexed educational science journals in the Web of Science database between 2007-2019 with the title "video games" by systematic review method. In this research, it is tried to determine the usage trends of video games in education.

\section{Design and Methodology}

By using the "Web of Science Core Collection" database as a data collection tool, it is provided to list the articles containing the words "video games" in the title. The period between 2007 and 2019 was selected in the Timespan section and only "SSCI" was selected in the "Web of Science Core Collection: Citation Indexes" section. At this stage, 868 studies are listed. Later, only articles were listed on the page opened, and only articles belonging to the discipline of educational sciences were listed by selecting the "Education Educational Research or Psychology Educational or Education Special or Education Scientific Disciplines" boxes in Web of Science categories. Following these selections, 69 articles were listed, but since 1 article was published in Spanish and 1 article was published in German, 67 articles were ultimately selected for systematic search. In this research, articles about video games were systematically reviewed. In analyzing and classifying articles according to specified criteria, 67 articles were analyzed by systematic review. The researcher consulted two volunteer experts who teach scientific research methods in order to increase the reliability of the research, especially in places where he had hesitation about the research methods used in the articles. While the articles in the literature were scanned systematically, frequencies from descriptive statistics were used and the analyzes were visualized with tables and graphics.

\section{Findings}

The articles were analyzed according to the their publication year, educational field, learning outcome obtained, name of video game, type of video game, device, environment, research method, data collection tool, sample group, number of samples, and theories / approaches / models. According to the results obtained from the findings, in 2017 and 2019, the number of publications reached the highest point, video games researches were made mostly in the science fields, mostly affective and motivational learning outcomes were obtained, You Make Me Sick! is the mostly played video game, mostly educational / serious game type is preferred, the games are played mostly in video game consoles, the applications are carried out in the classroom environment, quantitative methods are preferred as the method, the most common tests are used as the data collection tool, primary school students are selected as the sample group. It was found that a sample size of 0-50 was used and the game-based learning approach was preferred the most in these researches. It is seen that the researches carried out for the use of video games in the field of education are mostly published in Computers \& Education journal. When the types of video games are examined, the most intensive use of educational and serious games in educational research can be considered as a natural finding. However, apart from these games, it was concluded that different game types are used in educational environments. When looking at the technological devices where video games are played, it has been determined that video game consoles are used and Microsoft $\mathrm{Xbox}$ is the most preferred video console. It is seen that video game applications are mostly performed in 
classrooms, computer laboratories, science laboratories and homes. Looking at the methods used in studies related to video games in education, it is seen that the first quantitative, and then mixed, qualitative, theoretical, design-based and reviewing research are followed. In the articles, test, survey, interview, scale, observation, documents, focus group, online blog posts, delphi panels, concept maps, polls, short reports, messages, project data, card ratings and field notes were determined as the most used data collection tools.

\section{Research Limitations}

This research is limited to the SSCI in the Web of Science database. It is limited to the education field articles published between 2007-2019 with the keywords "video games" in its title. Also, it is limited to the systematic review method. The articles were examined by limiting to the following 12 dimensions: "Publication year", "educational field", "learning outcome", "name of the video game", "type of video game", "video game playing device", "video game playing environment" "research method", "data collection tool", "sample group", "sample size" and "theories / approaches / models".

\section{Implications (Theoretical, Practical and Social)}

When studies involving video games in education are examined, more studies including qualitative, theoretical and design-based methods can be suggested. In systematic review, it was observed that mostly students and teachers were used as samples in video game research. It can be suggested to use different sample groups in this kind of research. The number of samples is generally very high between 0-200; It can be said that it is necessary to work with larger sample groups. Apart from the features examined in this study, it may also be recommended to analyze additional features such as game developers, game publishers, game designers, game series, whether the game is in player mode (single player-multiplayer), whether it is commercial or free.

\section{Originality/Value}

Although this research has some common points with other studies in the literature in terms of the items examined, it was carried out in an original context both in terms of its scope and the years it was examined. The results of this study are important in terms of covering a relatively long period such as 2007 and 2019 and determining the latest situation in current studies. In addition, unlike other studies in the literature, it contains original findings in terms of analyzing some components such as the environments where video games are played, devices, theories / approaches / models used in research, which are not included in any study.

Araştırmacı Katkısı: Hakan Altınpulluk (\%100). 